\title{
Vulvovaginal candidiasis: Epidemiology, microbiology and risk factors
}

\author{
Bruna Gonçalves, Carina Ferreira, Carlos Tiago Alves, Mariana Henriques, Joana Azeredo, and Sónia Silva \\ CEB - Centre of Biological Engineering, LIBRO - Laboratório de Investigação em Biofilmes Rosário Oliveira, University of Minho, Braga, Portugal
}

\begin{abstract}
Vulvovaginal candidiasis (VVC) is an infection caused by Candida species that affects millions of women every year. Although Candida albicans is the main cause of VVC, the identification of non-Candida albicans Candida (NCAC) species, especially Candida glabrata, as the cause of this infection, appears to be increasing. The development of VVC is usually attributed to the disturbance of the balance between Candida vaginal colonization and host environment by physiological or nonphysiological changes. Several host-related and behavioral risk factors have been proposed as predisposing factors for VVC. Host-related factors include pregnancy, hormone replacement, uncontrolled diabetes, immunosuppression, antibiotics, glucocorticoids use and genetic predispositions. Behavioral risk factors include use of oral contraceptives, intrauterine device, spermicides and condoms and some habits of hygiene, clothing and sexual practices. Despite a growing list of recognized risk factors, much remains to be elucidated as the role of host versus microorganisms, in inducing VVC and its recurrence. Thus, this review provides information about the current state of knowledge on the risk factors that predispose to VVC, also including a revision of the epidemiology and microbiology of VVC, as well as of Candida virulence factors associated with vaginal pathogenicity.
\end{abstract}

\section{Keywords}

Behavioral factors, Candida species, host factors, vaginal infection, virulence factors

\section{History}

Received 29 April 2015

Revised 3 September 2015

Accepted 3 September 2015

Published online 28 October 2015

\section{Introduction}

Species from genus Candida have a wide distribution in nature and can be found in humans, domestic and wild animals as well as in diverse environments including hospitals (Sidrim \& Rocha, 2004). These yeasts belong to the normal flora of humans and can colonize the mucosal surfaces of the genital, urinary, respiratory and gastrointestinal tracts, as well as oral cavity, nails, scalp and skin (Dignani et al., 2009). However, Candida species can be commensal organisms or transform a symptomless colonization into an infection. Thus, these species are characterized as opportunistic and can change from harmless to pathogenic upon variation of the host conditions. Candida infections are mainly superficial, but in severely immunocompromised patients serious systemic infections can occur (Ascioglu et al., 2002). Most, if not all women carry Candida in vagina at some point of their lives, yet without symptoms of infection (Beigi et al., 2004). Candida organisms gain access to the lower genital tract mainly from the adjacent perianal area (Bertholf \& Stafford, 1983). There is a balance between Candida organisms and vaginal defence mechanisms against Candida, such as lactobacilli and immune responses that allow the persistence of Candida species as vaginal commensals (Ferrer, 2000), thereby changes in the host vaginal/vulvar environment

Address for correspondence: Sónia Silva, Minho University, Braga, Portugal. E-mail: soniasilva@deb.uminho.pt can lead to a Candida infection, named vulvovaginal candidiasis (VVC). VVC is defined as signs and symptoms of inflammation in the presence of Candida species and in the absence of other infectious agents (Achkar \& Fries, 2010). VVC can be classified into uncomplicated and complicated cases, a classification that has been accepted by several authors (Achkar \& Fries, 2010; Pappas et al., 2009; Sobel et al., 1998). Uncomplicated VVC is characterized by fewer than four episodes per year with mild to moderate severity caused by Candida albicans in apparently healthy women. Complicated VVC include episodes due to non-Candida albicans Candida (NCAC) species or severe cases caused by any Candida species. Moreover, recurrent VVC (RVVC), which is characterized by four or more episodes per year, and VVC in the presence of recognized risk factors (e.g. pregnancy, diabetes and immunosuppression) are also classified as complicated VVC (Achkar \& Fries, 2010; Pappas et al., 2009; Sobel et al., 1998).

The clinical symptoms of VVC are nonspecific and can be associated with a variety of other vaginal diseases, such as bacterial vaginosis, trichomoniasis and gonorrhea (Anderson, 2004). The most common clinical manifestations are vulvar pruritus and burning accompanied by vaginal soreness and irritation leading to dyspareunia and dysuria. Vulvar and vaginal erythema, edema and fissures are also commonly found (Sobel, 2005). Topical antimycotic agents (e.g. creams, lotions and vaginal suppositories) and oral therapy are available for VVC. Topical polyenes (e.g. nystatin) achieve a mycological cure rate of about 75-80\% and topical azoles of about 85-90\% (Sobel et al., 1995), in uncomplicated cases. 
Oral azole agents (e.g. fluconazole and itraconazole) achieve comparable cure rates than do topical agents (Watson et al., 2002) and most patients prefer the convenience of oral administration (Tooley, 1985). However, oral azoles have a potential side effect of toxicity (Fidel et al., 1999b). In addition, topical and oral azoles are poorly effective in VVC caused by Candida glabrata in comparison to C. albicans (Fidel et al., 1999b). In fact, complicated infections such as those caused by NCAC species or in the presence of risks factors are much more difficult to treat requiring intensive regimens (Sobel et al., 2001). Prevention treatments, such as topical vaginal use of recombinant mannose-binding lectin (Petersen et al., 2006) and anti-Candida vaccines (Spellberg et al., 2006), have been investigated as possible preventions for VVC.

VVC affects millions of women every year and has been considered an important public health problem. Although not associated with mortality, the morbidity associated with VVC makes it a major cause of mental distress, causing pain, great discomfort, altered self-esteem, anxiety, impairing work performance and interfering with sexual and affective relations (Sobel, 2007). VVC is also associated with considerable direct and indirect economic costs (Foxman et al., 2000) and enhanced susceptibility to human immunodeficiency virus (HIV) infection (Røttingen et al., 2001). Especially when VVC is left untreated, many complications has been appointed as its consequence, such as pelvic inflammatory disease, infertility, ectopic pregnancy, pelvic abscess, spontaneous abortion and menstrual disorders. Therefore, prevention, early diagnosis and prompt treatment of $\mathrm{VVC}$, especially among risk groups, are essential to avert the complications (Nwadioha et al., 2010).

Despite therapeutic advances VVC remains a common disease, for which triggering factors and their underlying mechanisms are not fully understood. Thus, this review provides information about the current state of knowledge on the risks factors predisposing to $\mathrm{VVC}$, also including a revision of the epidemiology and microbiology of VVC, as well as of Candida virulence factors associated with vaginal pathogenicity.

\section{Epidemiology of VVC}

VVC is not a reportable disease, and therefore, the information on its incidence is incomplete and based on epidemiology studies that are often hampered by inaccuracies of diagnosis and/or the use of non-representative populations (Sobel, 2007). VVC is considered the second most common cause of vaginitis after bacterial vaginosis (Anderson, 2004). It is estimated that approximately $10-15 \%$ of asymptomatic women are colonized with Candida, 70-75\% of women will experience an episode of $\mathrm{VVC}$ in their lifetimes, $50 \%$ of initially infected women will suffer a second VVC event and $5-10 \%$ of all women will develop RVVC (Sobel, 2007).

Symptoms and signs of VVC are not specific to the disease (Anderson, 2004) and the presence of Candida in the vagina is not necessarily indicative of VVC since asymptomatic women can be colonized. Therefore, the diagnosis of VVC requires correlation of clinical findings and laboratory confirmation of Candida. Table 1 highlights the more relevant epidemiologic studies published during the last years concerning the incidence of VVC diagnosed in symptomatic women with laboratory confirmation. It also shows the incidence of vaginal colonization by Candida species whenever asymptomatic women were also included in the study. The incidence of VVC in symptomatic women varies depending on the locations as well as the populations studied. The studies published during the last years reported incidences of the disease in symptomatic women that range from $12.1 \%$ to $57.3 \%$ (Table 1). The highest incidences were reported by epidemiologic studies made in African countries (Nigeria (Okungbowa et al., 2003) and Tunisia (Amouri et al., 2011), with 57.3\% and 48.0\%, respectively), followed by Brazil (Andrioli et al., 2009; Rosa \& Rumel, 2004) and Australia (Bradshaw et al., 2005). The lowest incidences were reported in European countries (Greece (Grigoriou et al., 2006) and Italy (Tibaldi et al., 2009), with 12.1 and $19.5 \%$, respectively) and India (17.7 to $20.4 \%$ ) (Ahmad \& Khan, 2009; Mohanty et al., 2007; Vijaya et al., 2014). All these epidemiologic studies were consensual in reporting higher incidence of $\mathrm{VVC}$ in women at reproductive age (20-40 years) than those at menopause. Regarding asymptomatic colonization, Brazilian (Andrioli et al., 2009;

Table 1. Epidemiologic studies published from 2003 to 2014, concerning the VVC incidence in symptomatic women and the incidence of vaginal colonization by Candida in asymptomatic women.

\begin{tabular}{|c|c|c|c|c|c|c|}
\hline Country & Year(s) of study & \multicolumn{2}{|c|}{ Symptomatic women } & \multicolumn{2}{|c|}{ Asymptomatic women } & References \\
\hline Brazil & 2002 & 23 & 43.5 & 112 & 14.3 & (Rosa \& Rumel, 2004) \\
\hline Jamaica & - & 422 & 29.6 & - & - & (Jackson et al., 2005) \\
\hline Italy & 1996-2005 & 13014 & 19.5 & 11551 & 11.6 & (Tibaldi et al., 2009) \\
\hline Austria & 2000-2004 & 10463 & 30.5 & - & - & (Paulitsch et al., 2006) \\
\hline India & 2003-2004 & 601 & 18.5 & - & - & (Mohanty et al., 2007) \\
\hline India & - & 1050 & 20.4 & - & - & (Ahmad \& Khan, 2009) \\
\hline India & 2011-2012 & 300 & 17.7 & - & - & (Vijaya et al., 2014) \\
\hline Israel & - & 208 & 35.5 & 100 & 15.0 & (Dan et al., 2003) \\
\hline Tunisia & $2006-2008$ & 481 & 48.0 & - & - & (Amouri et al., 2011) \\
\hline Nigeria & - & 902 & 57.3 & - & - & (Okungbowa et al., 2003) \\
\hline Australia & 2003-2004 & 342 & 42.7 & - & - & (Bradshaw et al., 2005) \\
\hline
\end{tabular}


Rosa \& Rumel, 2004), Italian (Tibaldi et al., 2009) and Israeli (Dan et al., 2003) studies reported vaginal colonization by Candida species in women without any symptoms of VVC with a prevalence between $11.6 \%$ and $17.0 \%$ (Table 1). VVC affects women globally, and therefore, further large studies, from diverse countries, are needed to a better knowledge of the incidence of VVC and vaginal asymptomatic colonization by Candida species.

\section{Microbiology of VVC}

The most common Candida species associated with VVC are C. albicans, C. glabrata, Candida tropicalis, Candida parapsilosis and Candida krusei. Typically, a single species is identified, but two or more species have been found in some women with VVC (1-10\%) (Amouri et al., 2011; Cetin et al., 2007; Fan et al., 2008b; Mahmoudi et al., 2011; Paulitsch et al., 2006; Richter et al., 2005). Most of these mixed infections are caused by an association between $C$. albicans and C. glabrata (Amouri et al., 2011; Mahmoudi et al., 2011; Paulitsch et al., 2006; Richter et al., 2005). In fact, C. albicans is the most common species identified in women with VVC followed by $C$. glabrata (Table 2). A recent ex vivo study demonstrated higher colonization and invasion of vaginal tissue by $C$. albicans than by $C$. glabrata, but an enhanced invasion by $C$. glabrata in co-infection with $C$. albicans (Figure 1) (Alves et al., 2014b).

Table 2 highlights the more relevant epidemiologic studies published during the last years concerning the distribution of the most common Candida species identified in women with VVC. Most of these studies reported higher association of C. albicans with VVC than NCAC species. In American (Richter et al., 2005), European (Corsello et al., 2003; Grigoriou et al., 2006; Paulitsch et al., 2006; Sojakova et al., 2004) and Australian (Holland et al., 2003) studies $C$. albicans was the most common specie identified in women with the disease (70.0-89.0\%), followed by C. glabrata (3.420.0\%). Also, Chinese (Fan et al., 2008b), Tunisian (Amouri et al., 2011) and Iranian (Mahmoudi et al., 2011) studies show a predominance of $C$. albicans (65.1-90.4\%), however in some Asian and African studies (Turkey (Cetin et al., 2007),
India (Ahmad \& Khan, 2009; Mohanty et al., 2007) and Nigeria (Okungbowa et al., 2003)), NCAC species appear to be more commonly associated with VVC, especially $C$. glabrata (29.5-50.4\%) (Table 2). Candida tropicalis is the second most common NCAC species, with the higher percentages identified in Nigeria (17.9\%) (Okungbowa et al., 2003), Jamaica (11.2\%) (Jackson et al., 2005) and India (10.8\%) (Mohanty et al., 2007).

Historically, 85-95\% of Candida species identified in women with VVC were C. albicans (Linhares et al., 2001; Lynch \& Sobel, 1994; Otero et al., 1998; Saporiti et al., 2001; Spinillo et al., 1997b); however, most studies, published during the last years, reported incidence of $C$. albicans below $85 \%$ and in some countries even below 50\% (Table 2). It has been suggested that the widespread and inappropriate use of antifungal treatments (self-medication and prolonged antifungal therapy) may lead to the selection of NCAC species (such as $C$. glabrata), which are more resistant to the commonly used antifungal agents than $C$. albicans (Sobel et al., 1998; Spinillo et al., 1994). In fact, NCAC species have been more commonly isolated among patients with RVVC than in women with sporadic VVC (Amouri et al., 2011; Grigoriou et al., 2006; Holland et al., 2003; Richter et al., 2005), possibly due to a higher antifungal exposure and widespread use of over the counter antimycotics among patients with RVVC (Nyirjesy et al., 1997). High percentages of NCAC species causing VVC, mainly $C$. glabrata, have been also associated with increasing age (Dan et al., 2006; Fan et al., 2008b; Holland et al., 2003), patients with uncontrolled diabetes (Goswami et al., 2000, 2006) and HIVinfected women (Corsello et al., 2003; Spinillo et al., 1997b). These associations are possible due to changes in patient physiology, hormone balance and decrease in immune functions.

Compared to $C$. albicans, NCAC species are generally associated with higher resistance to the azoles (Ribeiro et al., 2001; Richter et al., 2005; Sojakova et al., 2004), the most commonly prescribed class of antifungal agents. The use of nonazole antifungals, such as boric acid and flucytosine, has been shown to be effective in treating VVC caused by NCAC species, especially C. glabrata (Sobel et al., 2003), which

Table 2. Epidemiologic studies published from 2003 to 2014, concerning the distribution of Candida species in women with VVC.

\begin{tabular}{|c|c|c|c|c|c|c|c|c|}
\hline Country & $\begin{array}{l}\text { Year(s) of } \\
\text { study }\end{array}$ & $\begin{array}{c}\text { No. of } \\
\text { subjects }\end{array}$ & $\begin{array}{c}\text { C. albicans } \\
(\%)\end{array}$ & $\begin{array}{c}\text { C. glabrata } \\
(\%)\end{array}$ & $\begin{array}{c}\text { C. tropicalis } \\
(\%)\end{array}$ & $\begin{array}{c}\text { C. parapsilosis } \\
(\%)\end{array}$ & $\begin{array}{l}\text { C. krusei } \\
(\%)\end{array}$ & References \\
\hline USA & 1998-2001 & 429 & 75.7 & 15.6 & 1.1 & 3.8 & 3.8 & (Richter et al., 2005) \\
\hline Jamaica & - & 125 & 83.2 & 4.8 & 11.2 & - & - & (Jackson et al., 2005) \\
\hline Brazil & 2001-2003 & 40 & 70.0 & 20.0 & 7.5 & - & - & (Boatto et al., 2007) \\
\hline Italy & 1999-2001 & 909 & 77.1 & 14.6 & 2.3 & 0.6 & 4.0 & (Corsello et al., 2003) \\
\hline Slovakia & 2000-2001 & 227 & 87.7 & 6.2 & 0.9 & 0.9 & 2.2 & (Sojakova et al., 2004) \\
\hline Austria & 2000-2004 & 3243 & 87.9 & 3.4 & 0.2 & 0.5 & 0.3 & (Paulitsch et al., 2006) \\
\hline Greece & $2002-2004$ & 576 & 80.2 & 7.3 & 1.6 & 2.1 & 1.0 & (Grigoriou et al., 2006) \\
\hline Turkey & 2004-2005 & 240 & 44.2 & 29.6 & - & - & 5.8 & (Cetin et al., 2007) \\
\hline India & 2003-2004 & 111 & 35.1 & 50.4 & 10.8 & 0.9 & 2.7 & (Mohanty et al., 2007) \\
\hline India & - & 215 & 46.9 & 36.7 & 2.8 & 10.2 & 1.4 & (Ahmad \& Khan, 2009) \\
\hline China & 2003-2006 & 1070 & 90.4 & 7.9 & 0.9 & 0.6 & 0.1 & (Fan et al., 2008b) \\
\hline Iran & 2006-2008 & 175 & 65.1 & 13.1 & 6.2 & 0.6 & 4.0 & (Mahmoudi et al., 2011) \\
\hline Tunisia & 2006-2008 & 295 & 76.3 & 19.3 & 1.4 & - & - & (Amouri et al., 2011) \\
\hline Nigeria & - & 517 & 20.3 & 33.8 & 17.9 & 4.3 & - & (Okungbowa et al., 2003) \\
\hline Australia & 2000 & 1221 & 89.0 & 7.3 & 0.7 & 1.0 & 1.0 & (Holland et al., 2003) \\
\hline
\end{tabular}


Figure 1. Reconstituted human vaginal epithelium (RHVE) infected with $C$. albicans (A), with C. glabrata (B) and co-infected with $C$. albicans and C. glabrata (C) (Alves et al., 2014a).
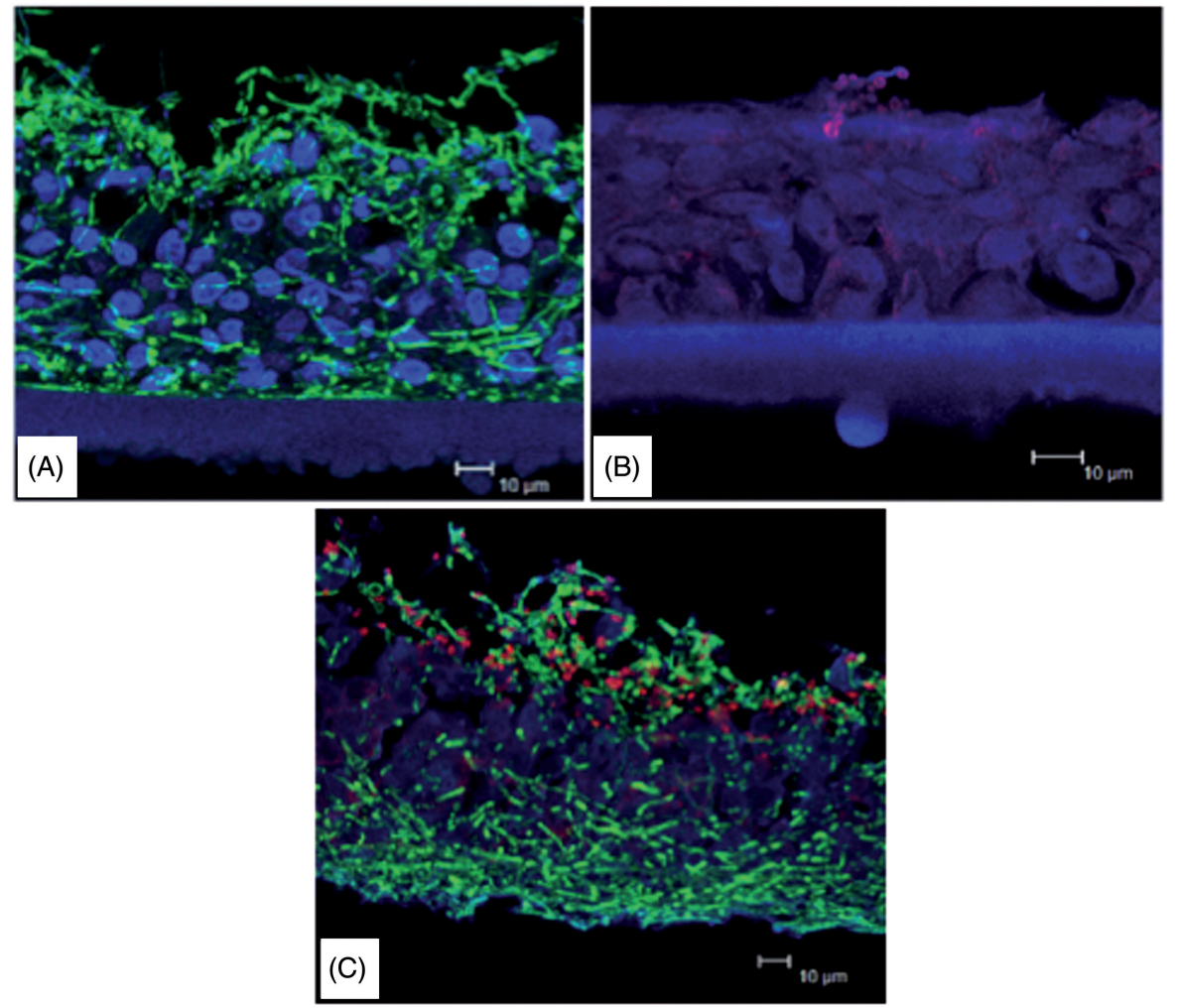

demonstrates intrinsically low susceptibility to the azoles and the ability to develop high resistance to them (Redding et al., 2003; Richter et al., 2005; Safdar et al., 2002). The high resistance levels of NCAC species to the commonly used treatments associated with an increasing identification of these species in women with VVC highlights the importance of identifying Candida species within vaginal samples, in order to provide physicians with information concerning the proper treatment for their patients.

\section{Candida virulence factors}

Until a few decades ago, it was believed that Candida microorganisms passively participated in the establishment of an opportunistic fungal infection, caused only by an organic weakness or an immunocompromised host. Today, there is consensus that these yeasts actively participate in the pathogenesis of the disease process, using mechanisms of aggression called virulence factors (Tamura et al., 2007). Thus, the pathogenicity of Candida species is mediated by a number of virulence factors that include adhesion, biofilm formation, extracellular hydrolytic enzyme production, hyphal formation and phenotypic switching.

\section{Adhesion}

Adhesion of Candida to host surfaces is required for initial colonization of human tissues, contributes to persistence of the microorganism within the host and is essential in the establishment of infection (Silva et al., 2012). Therefore, the primary event in VVC is the adhesion of Candida species to vaginal epithelial cells. Some studies have confirmed that Candida species have the ability to adhere to this type of cells (King et al., 1980; Vidotto et al., 2003). In addition, Candida species can adhere to the surface of medical devices, often promoting device-related infections, like VVC in women using intrauterine device (IUD) as contraceptive method (Demirezen et al., 2005). The initial attachment of Candida cells to biotic and abiotic surfaces is mediated by cell surface physicochemical properties and promoted by specific cell surface proteins, called adhesins (Verstrepen \& Klis, 2006). Adhesins recognize host ligands, such as serum proteins and components, of the extracellular matrix of host tissues (e.g. laminin, fibronectin, collagen, vitronectin and entactin), or promote the binding to abiotic surfaces through hydrophobic interactions (Chaffin, 2008). In C. albicans, a major group of adhesins is encoded by the agglutinin-like sequence ( $A L S)$ gene family that comprises eight members (ALS1-7, 9) (Hoyer et al., 2008). Cheng et al. (2005) detected expression of all $A L S$ genes in vaginal specimens of women with VVC, but expressions of $A L S 1, A L S 2, A L S 3$ and $A L S 9$ were detected more frequently than of $A L S 4$ to $A L S 7$. These investigators also demonstrated that the expression of $C$. albicans ALS genes has host-site specific influences. In $C$. glabrata, up to 23 different genes encoding epithelial adhesins (EPA gene family) were already identified, and three genes, EPA1, EPA6 and EPA7, have been shown to encode functional adhesins (Cormack et al., 1999). Alves et al. (2014b) detected expression of these three genes in reconstituted human vaginal epithelium (RHVE) infected with $C$. glabrata, with the highest value exhibited by EPA1. These investigators also detected all ALS genes in RHVE infected with $C$. albicans, with the highest expression exhibited by ALS3 and ALS6 and the lowest by $A L S 7$. Interestingly, in RHVE co-infected with $C$. glabrata and $C$. albicans the EPA genes were downregulated or absent and $A L S$ genes were generally similar to those observed in single infection, with the exception of a 
highly increase in $A L S 3$ expression. These results suggest that probably $A L S 3$ but not EPA adhesins are associated with the enhanced RHVE invasion by $C$. glabrata observed in the presence of $C$. albicans. In $C$. parapsilosis, 11 genes were identified for putative cell wall adhesins-like proteins (Butler et al., 2009) and at least three Als proteins were identified in C. tropicalis and Candida dubliniensis (Hoyer et al., 2001). However, in most NCAC species, the function of identified adhesins was still poorly studied. The absence of in vitro animal-human models highlights the importance to deepen and validate the information reported on those in vitro studies.

\section{Biofilm formation}

Adhesion of Candida cells to host epithelium or medical devices has been implicated as an early step in biofilm formation. Biofilms are structured communities of microorganisms, irreversibly attached to a surface, with a high degree of organization and a self-produced extracellular matrix (Douglas, 2003). Biofilms are the most prevalent growth form of microorganisms in nature, with up to $80 \%$ of all microorganisms, in the environment, existing in biofilm communities. It is also suggested that over $65 \%$ of all human infections are related to microbial biofilms (Donlan, 2002). Biofilm formation is an important virulence factor for Candida species as it confers unique phenotypic characteristics compared to their planktonic counterpart cells including significant resistance to antifungal agents, host defence mechanisms and physical and chemical stress (Donlan \& Costerton, 2002). Furthermore, biofilm cells exhibit metabolic cooperation, community-based regulation of gene expression and the ability to withstand the competitive pressure from other organisms (Davey \& O'toole, 2000; Ramage et al., 2009). The association of microorganisms into biofilms is a form of protection for their development and contributes to their survival in hostile environmental conditions (Davey \& O'toole, 2000). Clinically, the most important phenotype of biofilms is their extraordinary resistance to the conventional antifungal therapy, which has been reported to be up to 1000-fold higher than of their planktonic counterpart cells (Ramage et al., 2009). However, the resistance mechanisms of Candida biofilms to antifungal therapy are not fully understood. It is accepted that the antifungal resistance of biofilms is a complex multifactorial phenomenon that includes alterations or overexpression of target molecules, active extrusion of antifungal agents through efflux pumps and their limited diffusion in the matrix, stress tolerance, cell density and presence of persister cells (Ramage at al., 2012). Formation of mature biofilms and subsequent production of extracellular matrix is strongly dependent on species, strains and environmental conditions (Jain et al., 2007; Silva et al., 2009). Concerning the vaginal environment, Candida species can form biofilms on vaginal epithelium (Harriott et al., 2010) and have high capacity to produce biofilms on IUDs promoting VVC (Chassot et al., 2008; Lal et al., 2008). Candida biofilms have been studied primarily on abiotic surfaces because almost all device-related infections involve growth in the form of biofilm (Dominic et al., 2007). Recently, biofilm formation on biotic surfaces has received some attention, and Harriott et al. (2010) showed for the first time that $C$. albicans forms biofilms in vivo on vaginal mucosa. These investigators also reported that Candida biofilm formation on the vaginal mucosa in vivo requires regulators of biofilm formation $(B C R 1)$ and morphogenesis (EFG1), which had been previously identified as necessary genes for biofilm formation on abiotic surfaces (Nobile et al., 2006; Ramage et al., 2002). The ability of Candida species to form biofilms on the vaginal mucosa is an important clinical issue since the recalcitrance of these biofilms to the conventional antifungal therapy may prevent complete eradication of the microorganisms from the vaginal lumen and might explain the frequent recurrence of VVC. In addition, it has been realized that many Candida infections are directly linked to biofilms in which multiple species coexist, making the therapeutic management of these infections extremely difficult. Most studies are on monospecies biofilms of Candida, and information on mixed-species Candida biofilms or Candida-bacteria combinations is still scarce (Thein et al., 2009). Mixed-species biofilms can be difficult to both diagnose and treat, requiring complex multidrug treatment strategies. Mixed biofilms, especially Candida-bacteria biofilms, can cause a dilemma for clinicians because antimicrobials directed towards one species often facilitate non-targeted organisms to continue the infection (Thein et al., 2009). Studies report that both Candida species (Harriott et al., 2010) and vaginal bacterial pathogens as Gardenerella vaginalis (Scott et al., 1989; Swidsinski, 2008), which cause bacterial vaginosis (BV), have the ability to form biofilms on the vaginal mucosa. However, the formation of mixed Candida-bacteria biofilms on the vaginal mucosa is still understudied. Some studies have shown that approximately 20-34\% of RVVC samples contain vaginal bacterial pathogens such as Streptococcus agalactiae and $G$. vaginalis (Buchta \& Spacek, 2004; Esim et al., 2010), possibly due to mixed biofilms with Candida and these bacteria. Concerning mixed biofilm formation on IUDs, a survey on biofilms formed on those devices confirmed the presence of C. albicans as well as multiple bacterial pathogens such as S. agalactiae, Escherichia coli and Bacteroides species (Pál et al., 2005). Although vaginal infections are an extremely common reason for women to seek care, there is little known about the prevalence of mixed infections, particularly VVC and BV. Recently, Rivers et al. (2011) published the first article to present the prevalence of $\mathrm{BV}$, VVC, yeast colonization and mixed infection. In this study, BV was diagnosed in $72.5 \%$ of the participants and VVC in $15.7 \%$. Among women with BV, $33.1 \%$ were colonized with yeast and the overall prevalence of BV/VVC mixed infection was $4.4 \%$. The authors suggested that the presence of infection/colonization with yeasts likely predisposes women to VVC after treatment of BV with antibiotics. In fact, some studies reveal that $\mathrm{VVC}$ is a common side effect of $\mathrm{BV}$ treatment with metronidazole or clindamycin (Bradshaw et al., 2006; Sobel \& Leamna, 1998). Thus, women with $\mathrm{BV}$ that also have yeast residing in the vaginal ecosystem can either exhibit failure of symptom resolution from therapy targeted at one infection or development of VVC from exposure to antibiotics. The little information available on the prevalence of vaginal mixed infections is likely due to the fact that most vaginal infections are diagnosed empirically without 
the aid of objective data. The lack of awareness as to the extent of this problem likely leads to under recognition of mixed infections, resulting in inadequate therapy.

\section{Extracellular hydrolytic enzyme production}

Candida species secrete several hydrolytic enzymes, which play an important role in adhesion, tissue penetration, invasion and destruction of host tissues (Schaller et al., 2005). The enzymes most frequently implicated in Candida pathogenicity are secreted aspartyl proteinases (Saps), but phospholipases, lipases and haemolysins are also involved in Candida virulence (Silva et al., 2012). Saps facilitate adhesion to host tissues and their damage and are related with changes in the host immune response (Pichová et al., 2001). To date, 10 SAP genes (SAP1-10) were identified in C. albicans (Odds, 2008), three (SAPP1-3) in C. parapsilosis (Merkerová et al., 2006) and at least four (SAPT1-4) in C. tropicalis (Togni et al., 1991; Zaugg et al., 2001), but in NCAC species, most of the genes remains uncharacterized. In the case of $C$. glabrata, only one study demonstrated ability of this species to produce proteinases, but the type of proteinase remains unknown (Chakrabarti et al., 1991). In contrast with other types of proteinases, Saps show proteinase activity only under acid conditions $(\mathrm{pH} \leq 4.0)$ (Williams et al., 2011). This feature is important for VVC, because the vaginal environment is acidic (pH around 4) (Sobel, 2005), providing conditions suitable for activity of Saps. Mohandas and Ballal (2011) detected higher proteinase activity in vaginal isolates than in urinary and respiratory isolates, of candidiasisinfected patients, relating Sap production and site of strain isolation. Furthermore, several studies have reported higher expression of SAPS and higher proteinase activity by Candida species isolated from women with VVC than from asymptomatic vaginal Candida carriers (Cassone et al., 1987; De Bernardis et al., 1990; Ozcan et al., 2006). It has been also demonstrated that the expression of $C$. albicans $S A P 1-3$ has a strong and specific correlation with VVC (Lian \& Liu, 2007; Naglik et al., 2003; Schaller et al., 2003). Phospholipases hydrolyze one or more ester bonds in glycerophospholipids contributing to host-cell membrane damage and to the adhesion of yeasts to host tissues. Several Candida species have the ability to produce extracellular phospholipases, but this ability is highly strain dependent and NCAC species produce significantly lower levels compared with $C$. albicans (Ghannoum, 2000). Mohandas and Ballal (2011) found a greater number of phospholipase producing strains in vaginal isolates of patients with candidiasis than in respiratory and skin isolates. In $C$. albicans, seven phospholipase genes have been reported (PLA, PLB1-2, PLC1-3 and PLD1) (Samaranayake et al., 2006). Naglik et al. (2003) detected expression of PLB1 and PLB2 in vaginal washes of VVC infected women and of asymptomatic vaginal Candida carriers, reporting lower levels in healthy women. Furthermore, Alves et al. (2014b) detected expression of $P L B$ and PLD gene families in RHVE infected with several $C$. albicans strains. The highest expression level was exhibited by PLDI indicating a potential role of this factor in RHVE damage. Lipases are involved in the hydrolysis of triacylglycerols and their activity has been associated to Candida adhesion and damage of host tissues and affects immune cells (Stehr et al., 2004). In C. albicans, lipases are coded by 10 genes (LIP1-10), similar sequences were identified in $C$. tropicalis and two lipase genes were detected in $C$. parapsilosis (CpLIP1-2), but none in C. glabrata (Silva et al., 2012). These enzymes are less studied than Saps and phospholipases, especially concerning their specific association with the anatomical site of infection. Haemolysins produced by Candida species degrade haemoglobin, facilitating recovery of iron, being essential to survival and persistence in the host. The production of these proteins was already described in several Candida species, including C. albicans, C. glabrata, C. parapsilosis and C. tropicalis; however, the genetic expression of haemolytic activity is poorly understood (Luo et al., 2004).

\section{Hyphae formation}

A reversible morphological alternation between unicellular yeast cells and filamentous phase (hyphae and pseudohyphae) is an important virulence factor of some Candida species (Silva et al., 2012). Candida albicans and C. dubliniensis have the ability to form hyphae and/or pseudohyphae, $C$. parapsilosis can generate pesudohyphae, $C$. tropicalis pesudohyphae and possibly true hyphae and $C$. glabrata grows only as blastoconidia (Silva et al., 2012). Filamentous forms give more mechanical strength, enhancing colonization and invasion of host tissues and demonstrate increased resistance to phagocytosis (Kumamoto \& Vinces, 2005; Silva et al., 2012). Hyphae are believed to play an important role in tissue invasion, and in vitro research has shown that $C$. albicans lacking hyphal formation exhibited lower ability to invade tissue compared to the wild-type strains (Jayatilake et al., 2006). The yeast-hyphal switch is affected by environmental factors and is related with other virulence factors. For instance, phospholipase D (PLDl) is necessary for yeastto-hyphal transition in C. albicans (Hostetter, 1994) and the expression of some SAP genes (SAP4-6) occur specifically during hyphal development (Hube et al., 1997). Taylor et al. (2005) detected association of SAP4 and SAP5 expression with hyphal formation during vaginal candidiasis in mice. Furthermore, Alves et al. (2014b) in a study with RHVE infected with $C$. albicans detected expression of the hyphal wall protein $(H W P 1)$ gene, which is a specific hyphae-adhesin responsible for a covalent attachment of the yeast to host epithelial cells. Interestingly, in RHVE co-infected with $C$. albicans and $C$. glabrata, being the latter a nonhyphae producer, the investigators detected an up-regulation of HWPI that may have contributed for the enhanced tissue invasion by $C$. glabrata observed in the presence of $C$. albicans.

\section{Phenotypic switching}

The colonies of most Candida species can switch among different phenotypes at high frequency. In $C$. albicans whitephase round-ovoid cells can switch to opaque-phase cells which are elongated or bean-shaped (Anderson \& Soll, 1987). It has been identified that the genes MTLa1-2, WORI-2, $C Z F 1$ and EFG1 regulate the white to opaque switching (Zordan et al., 2006, 2007). Furthermore SAP3 and EFGl are expressed specifically in white cells whereas SAP1-2 are 
expressed specifically in opaque cells (Soll, 1997). Comparatively to $C$. albicans the phenotypic switching of NCAC species is less understood. It has been reported that C. glabrata can undergo "core switching" that results in white, light brown, dark brown, very dark brown or irregular wrinkle colonies. Brockert et al. (2003) showed a predominance of dark brown colonies among vaginal isolates of patients with VVC. The phenotypic switching alters several virulence traits including hyphae formation (Anderson et al., 1989), drug resistance (Vargas et al., 2000), adhesion and Saps secretion (Morrow et al., 1992), potentially affecting survival in specific anatomical sites and promoting infection. The precise contribution of phenotypic switching to VVC is still not clear, but it has been demonstrated that vaginal isolates obtained during VVC and RVVC are in highfrequency mode of switching (Soll, 1988; Soll et al., 1987, 1989). Furthermore, in each recurrence of one patient with RVVC, different colony phenotypes were observed but DNA genotyping remained identical (Soll et al., 1989).

All virulence factors that mediate Candida pathogenicity are influenced by the specific environmental conditions of each anatomical site. Thus, the disturbance of the normal environment of the lower female genital tract may increase the risk of infection by Candida species. Next will be reviewed the knowledge about risks factors predisposing for VVC.

\section{Risk factors for VVC}

The vaginal flora is highly dynamic with a local microbial system. There is a balance between Candida vaginal colonization and the host environment that can be disturbed by physiological or non-physiological changes, making the colonization site favorable for the development of yeasts. Healthy women can develop VVC sporadically however this infection is often attributed to the presence of host-related and behavioral factors that disturb the vaginal environment, promoting VVC. Proposed host-related risk factors include pregnancy, hormone replacement, uncontrolled diabetes mellitus, imunosuppression, antibiotics and glucocorticoids use and genetic predispositions (Sobel, 2007) (Figure 2). Behavioral risks factors for VVC include use of oral contraceptives, intrauterine device, spermicides and condoms, and also some sexual, hygienic and clothing habits (Patel et al., 2004; Sobel, 2007) (Figure 3).

\section{Host factors}

\section{Pregnancy and hormone replacement therapy}

Pregnancy has been considered an important risk factor for the development of VVC because several studies report high incidence of the disease in pregnant women. Table 3 shows studies published during the last years, concerning the incidence of VVC in pregnant and nonpregnant women. The epidemiologic studies have been consensual in reporting higher prevalence of the disease in pregnant women than in non-pregnant patients, although the incidence varies depending on the locations. In the last years, most studies of VVC incidence in pregnant women were made in India and Nigeria (Table 3), probably because these countries have high birth rate and thus, have interest to study pregnant-related diseases. In Indian studies (Ahmad \& Khan, 2009; Neerja et al., 2006; Vijaya et al., 2014), the incidence of VVC in pregnancy ranges between $10.0 \%$ and $76.0 \%$ and in nonpregnancy between $7.7 \%$ and $31.0 \%$. A Nigerian study (Kamath et al., 2013) reported an incidence of VVC in pregnancy and nonpregnancy of $47.7 \%$ and $20.3 \%$, respectively, and Greek (Grigoriou et al., 2006) and Belgian (Bauters et al., 2002) studies reported a little less incidence of the disease in both conditions. Two Nigerian reports (Nwadioha et al., 2010; Shu'aibu et al., 2014) and a Kenyan one (Nelson et al., 2013) only included the incidence of $\mathrm{VVC}$ in pregnant women without a non-pregnant control, but all of them reported high incidence of the disease in pregnancy (Table 3 ). In addition, since the vaginal colonization is a prerequisite for symptomatic VVC, some studies have also studied the incidence of Candida colonization in nonsymptomatic pregnant women. These studies reported higher prevalence of vaginal colonization by Candida in pregnant women than in those who were not pregnant, indicating that pregnancy increases vaginal colonization (Cotch et al., 1998; Jabeen \& Siddiqi, 2014).

The high incidence of VVC in pregnancy has been attributed to the increase of sex hormones secretion in pregnancy. In fact, during pregnancy, VVC prevalence is

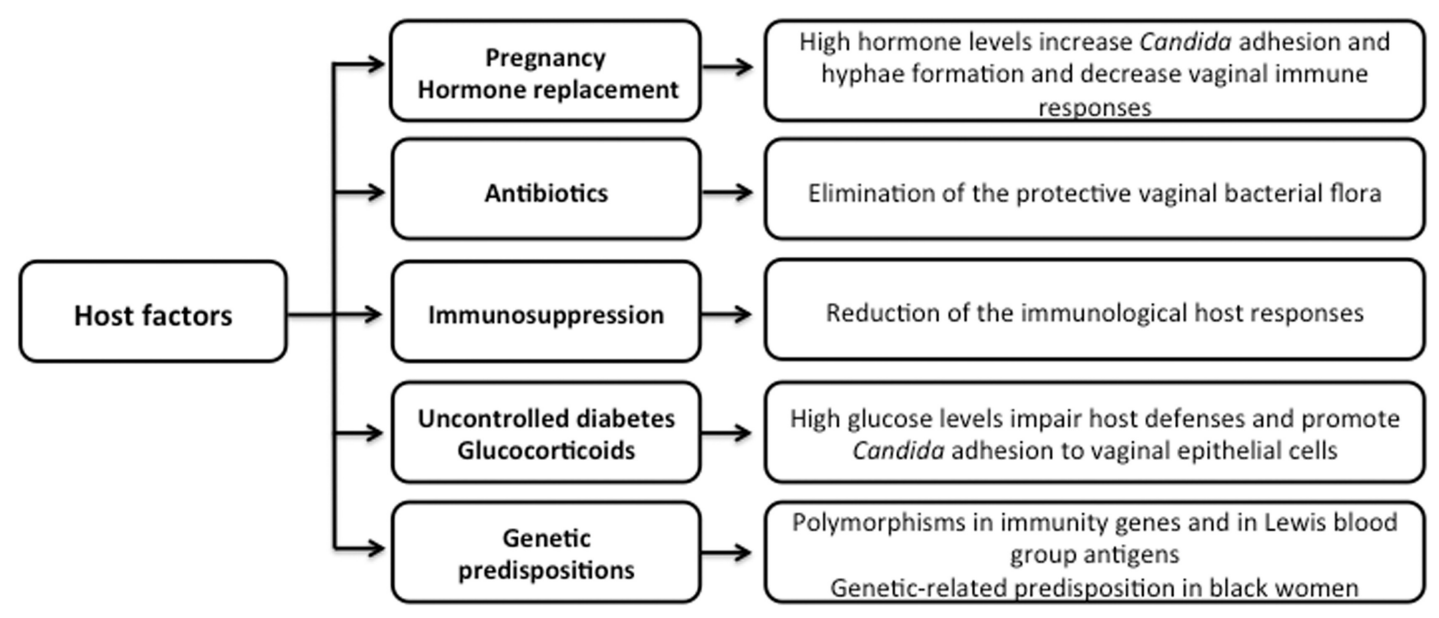

Figure 2. Host-related risk factors for vulvovaginal candidiasis and respective effects. 


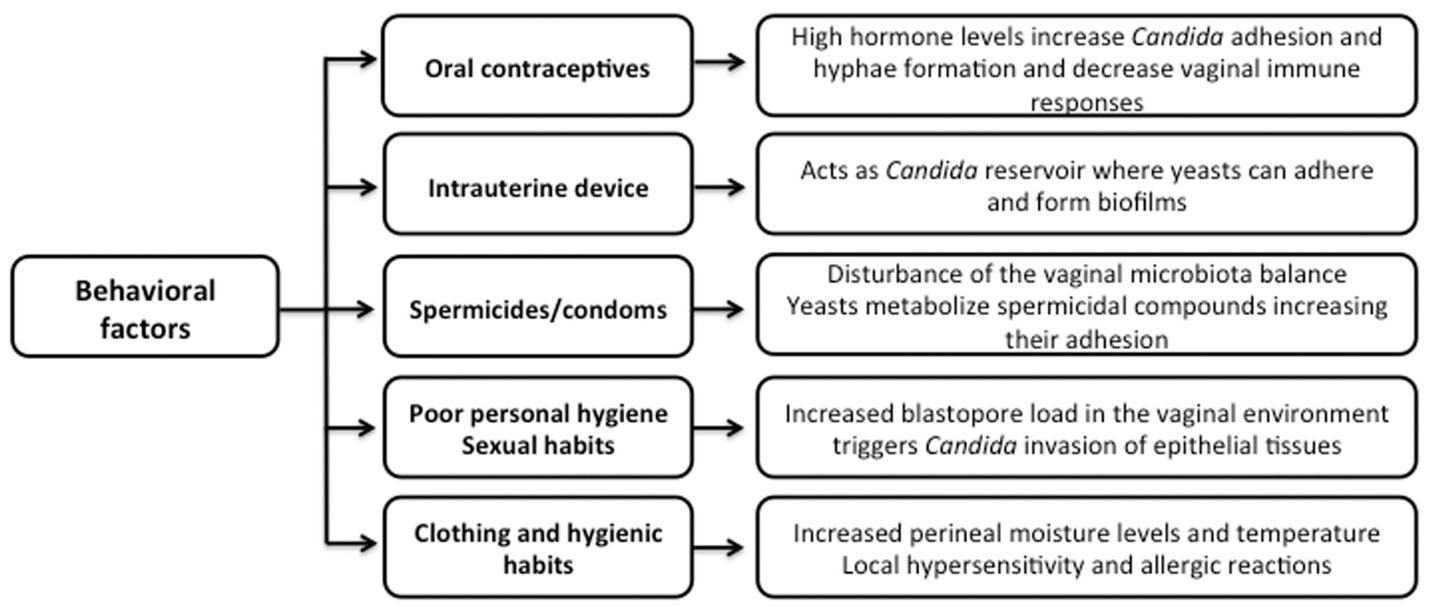

Figure 3. Behavioral risk factors for vulvovaginal candidiasis and respective effects.

Table 3. Incidence of VVC in pregnant and nonpregnant women reported in studies published from 2002 to 2014.

\begin{tabular}{lcccc}
\hline Country & Year(s) of study & Pregnant women $(\%$ with VVC) & Non-pregnant women (\% with VVC) & References \\
\hline India & $2011-2012$ & 10.0 & 7.7 & (Vijaya et al., 2014) \\
India & - & 28.2 & 7.9 & (Neerja et al., 2006) \\
India & - & 76.0 & 31.0 & (Ahmad \& Khan, 2009) \\
Greece & $2002-2004$ & 29.1 & 7.9 & (Grigoriou et al., 2006) \\
Belgium & - & 32.0 & 20.3 & (Bauters et al., 2002) \\
Nigeria & 2009 & 47.7 & Not included & (Kamath et al., 2013) \\
Nigeria & $2006-2007$ & 40.0 & Not included & (Nwadioha et al., 2010) \\
Nigeria & - & 91.0 & Not included & (Shu'aibu et al., 2014) \\
Kenya & 2010 & 90.4 & & (Nelson et al., 2013) \\
\hline
\end{tabular}

higher in the last trimester, when levels of hormones are more elevated, even though symptomatic recurrences are common throughout pregnancy (Bauters et al., 2002; Nelson et al., 2013). Furthermore, in nonpregnant women the infection is more incident during the luteal phase of the menstrual cycle, which is the phase with the highest hormone secretion (Eckert, 1998; Kalo-Klein \& Witkin, 1989). Kalo and Segal (1988) also demonstrated that the level of in vitro adherence of $C$. albicans to human vaginal exfoliated cells (VEC) has a correlation with the hormonal status of the cell donors, being higher in VEC of pregnant women and of those in luteal phase of the menstrual cycle. The hormonal dependence of VVC is also evidenced by the fact that the disease is uncommon in pre-puberty and post-menopause, except in women taking hormone replacement therapy (HRT) (Bauters et al., 2002; Tibaldi et al., 2009). HRT is used to counter adverse the consequences associated with the decrease in hormones secretion in postmenopause, such as osteoporosis, diabetes mellitus, cardiovascular disease and neurodegeneration (McNagny, 1999; Psaty, 1993); however, it has been considered a risk factor for the development of VVC. Higher incidence of VVC has been reported in women receiving HRT (26.0-29.4\%) than in post-menopausal women without HRT (4-12.6\%) (Bauters et al., 2002; Dennerstein \& Ellis, 2001; Spinillo et al., 1997a). All authors agree that the high hormonal levels of pregnant women and of those receiving HRT are the main factors responsible for the relation of those conditions with VVC. However, emotional stress, suppression of immune system and eating habits of sugar-rich food may also contribute to the development of VVC in those women (Sobel et al., 1998).

The two types of female sex hormones are estrogens and progestins. The most important progestin is progesterone, which is secreted by the corpus luteum, placenta and by adrenal cortex. During the luteal phase of the menstrual cycle, significant amounts of progesterone are secreted and during pregnancy its levels increase about 10 times. Progesterone is important in many vital actions of the woman, such as endometrial and breast development, maintenance of pregnancy, decrease in insulin action and increase in sodium excretion by the kidneys (Guyton \& Hall, 2006). The main estrogen in pre-menopause is $\beta$-estradiol and in postmenopause is estrona, which has a lower estrogenic potency than $\beta$-estradiol. Significant amounts of estrogens are secreted by the ovaries and during pregnancy high amounts of these hormones are secreted by the placenta increasing about 30 times their levels. Estrogens perform many essential actions in women, including the development of secondary sex characteristics, uterine growth and conservation of the vaginal mucosa (Guyton \& Hall, 2006). Despite being accepted that VVC has a hormonal dependency, the mechanisms by which progesterone and estrogens act in the disease are not fully understood. One proposed mechanism is associated with the increase in glycogen load in vaginal epithelium when the levels of progesterone and estrogens increase. The walls of vagina are lined with the pavement of epithelial cells, which produce glycogen in proportion to hormonal levels, and thus the state of the vaginal mucosa reflects female hormonal 
status in different lifetime stages (Dennerstein \& Ellis, 2001). The production of glycogen by hormone stimulated epithelium possibly contributes to the proliferation of Candida species when host hormones exceed a certain level, because glycogen provides an excellent nutritional source of carbon for Candida growth (Dennerstein \& Ellis, 2001; Spacek et al., 2007). In addition to the effect on vaginal epithelium, it has been also proposed that sex hormones inhibit aspects of both innate and adaptive immunity at systemic or local level. In fact, studies in vitro with vaginal epithelial cells found that progesterone and estrogens inhibit Candida-specific human peripheral blood lymphocyte (PBL) responses (Kalo-Klein \& Witkin, 1989, 1991) and that estradiol significantly reduces antimicrobials production (HBD2 and elafin) (Wira \& Fahey, 2008). Furthermore, analyses of cervical-vaginal secretions demonstrate that chemokines and cytokines (IL-6 and IL-8), antimicrobials (HBD2 and lactoferrin) and levels of $\operatorname{IgA}$ and $\mathrm{IgG}$ antibodies are depressed by 10 - to 100 -fold at mid-cycle, remain depressed for 7-10 days and rise to proliferative levels in the end of the menstrual cycle (Fleetwood et al., 1984; Keller et al., 2007). In addition, Nohmi et al. (1995) reported that physiological blood level of progesterone of pregnant women clearly suppresses mice neutrophil anti-Candida activity.

Besides the effects on the host, it has also been shown that progesterone and estrogens have direct effects on Candida cells, possibly contributing to VVC. One direct effect of the hormones is the stimulation of estrogen and progesterone cytosolic receptors, which have been already identified in several Candida species. An estrogen-binding protein (EBP), that displays high affinity for estradiol and estrone, was identified and characterized in C. albicans (Skowronski \& Feldman, 1989; Wagner \& Johnson, 2012) and an estrogenbinding system was also detected in C. glabrata (Powell et al., 1984). In addition, a corticosteroid-binding protein (CBP) that exhibits high affinity for corticosterone and progesterone, but low affinity for estrogens, was identified in $C$. albicans, $C$. guilliermondii, C. krusei, C. parapsilosis and C. tropicalis (Loose et al., 1983; Skowronski \& Feldman, 1989). The highest binding capacity is exhibited by $C$. guilliermondii, C. parapsilosis and C. albicans (Loose et al., 1983). Reed (1992) showed that when progesterone receptors are stimulated there is an increase in Candida proliferation. However, recently, Alves et al. (2014a) contradicted these results showing that the presence of progesterone reduces the ability of $C$. albicans to develop biofilms and hyphal forms (Figure 4) as well as decreases the expression levels of biofilm related genes $B C R 1$ and $H W P 1$. These investigators also showed that $C$. albicans colonization and invasion of
RHVE decreased substantially in the presence of progesterone. In accordance with Alves et al. (2014a); Spacek et al. (2007) found lower progesterone levels in patients with RVVC than in healthy controls and Nohmi et al. (1995) showed that progesterone contribute to $C$. albicans growth form conversion from hyphal to yeast. Furthermore, Fidel et al. (2000) reported that progesterone has no effect on the induction and persistence of vaginal infection and that estrogen is the dominant reproductive hormone that supports and sustains an experimental vaginal $C$. albicans infection. In fact, in vitro studies show that $\beta$-estradiol increases $C$. albicans growth (Zhang et al., 2000) and directly stimulates the dimorphic transition from yeast to hyphal form also increasing hyphae length (Cheng et al., 2006; White \& Larsen, 1997). Madani et al. (1994) demonstrated that estradiol inhibits the NADPH oxidase activity associated with $E B P 1$, which might indicate that the inhibition of this enzyme may lead to metabolic changes favoring the yeasthyphal conversion or blocking the inverse change. Furthermore, it has been also shown that estradiol increases C. albicans expression of $C D R 1$ and $C D R 2$, which encode multidrug transporters of the $\mathrm{ABC}$ family, suggesting that estradiol might be also involved in C. albicans drug resistance (Cheng et al., 2006; Zhang et al., 2000).

Since VVC incidence is higher and cure rates are lower in conditions with high hormone levels such as pregnancy and HRT, therapy must be appropriate for these patients. VVC in pregnancy does not usually harm the unborn child but if the disease is not treated the baby can get infected (oral trush) during delivery, which can be a very serious health problem in premature babies. Furthermore, infants with oral trush can give rise to nipple candidiasis in breast-feeding mothers (Parveen et al., 2008). In addition, some authors report reduction of preterm birth in pregnant women treated for VVC with clotrimazole (Czeizel \& Rockenbauer, 1999; Czeizel et al., 2004). It is has been also shown that a large proportion of women with RVVC first appear with the infection during pregnancy (Mitchell, 2004). Thus, in order to avert the complications associated with VVC in risk groups such as pregnant women and those with HRT early diagnosis and prompt treatment are very important.

\section{Antibiotics}

The use of antibiotics (vaginal or systemic) has been considered a risk factor for the development of VVC (Barbone et al., 1990; Geiger \& Foxman, 1996). Table 4 highlights the most relevant reports that studied the
Figure 4. Scanning electron microscopy images of $C$. albicans ATCC biofilms formed in the absence (A) or presence (B) of $2 \mu \mathrm{M}$ of progesterone. Original magnification was $\times 1000$ and the scale bars correspond to $20 \mu \mathrm{m}$ (Alves et al., 2014a).
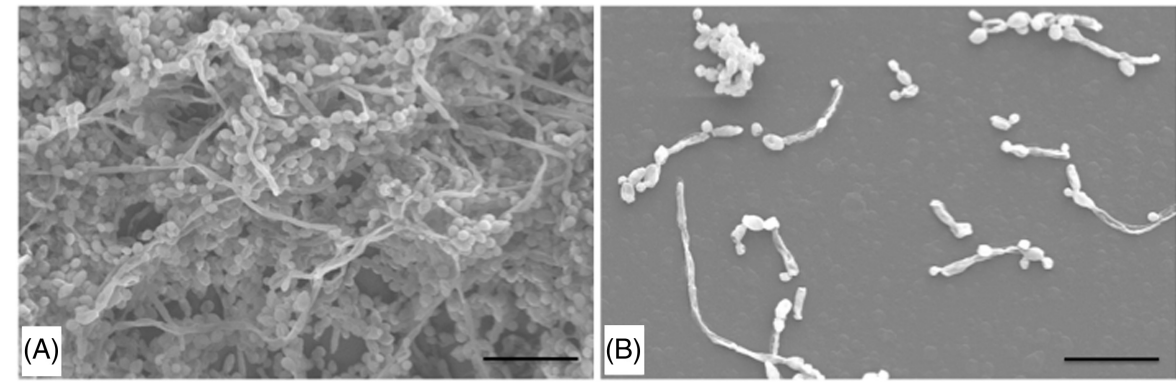
Table 4. Incidence of VVC in women that used and not used antibiotics and incidence of antibiotic use in women with and without VVC.

\begin{tabular}{|c|c|c|c|c|c|c|}
\hline Country & Year(s) of study & \multicolumn{2}{|c|}{ Incidence of VVC (\%) } & \multicolumn{2}{|c|}{ Incidence of antibiotic use (\%) } & References \\
\hline India & - & 57.5 & 11.8 & ni & ni & (Ahmad \& Khan, 2009) \\
\hline Italy & $1991-1997$ & 55.2 & 41.0 & 19.3 & 11.9 & (Spinillo et al., 1999) \\
\hline Italy & 1989-1994 & 45.5 & 39.2 & 18.3 & 11.4 & (Spinillo et al., 1995) \\
\hline Turkey & 2009-2010 & ni & ni & 29.5 & 6.8 & (Guzel et al., 2011) \\
\hline Nigeria & 2006-2007 & ni & ni & 16.0 & ns & (Nwadioha et al., 2010) \\
\hline Israel & - & $\mathrm{ni}$ & $\mathrm{ni}$ & 23.0 & ns & (Dan et al., 2003) \\
\hline
\end{tabular}

ni - not included in the study; ns - not shown in the study

prevalence of VVC in women treated and untreated with antibiotics and the incidence of antibiotic use. Studies in India (Ahmad \& Khan, 2009), Greece (Grigoriou et al., 2006) and Italy (Spinillo et al., 1995, 1999) showed an increased incidence of VVC in women that have taken antibiotics than in those who have not taken antibiotics $(18.0-57.5 \%$ versus 8.2-41.0\%). Studies in Italy (Spinillo et al., 1995, 1999), Turkey (Guzel et al., 2011), Brazil (Linhares et al., 2001), USA (Eckert, 1998), Nigeria (Nwadioha et al., 2010) and Israel (Dan et al., 2003) showed an increased incidence of antibiotic use in women with VVC than without VVC (8.2-29.5\% versus $0.7-11.9 \%)$. These epidemiologic data may have been influenced not only by the location where the study was made but also by type of antibiotic used and the duration of the treatment. In fact, the duration of antibiotic use is directly related to an increase in VVC prevalence (Spinillo et al., 1999). Moreover, broad-spectrum antibiotics (e.g. tetracycline, ampicillin and cephalosporin) are more likely to favor yeast infections compared with narrow-spectrum antibiotics (e.g. erythromycin, lincomycin) (Bluestein et al., 1991). Furthermore, it has been shown that antibiotic agents also predispose to RVVC (Guzel et al., 2011; Spinillo et al., 1995, 1999), in some cases with more significance than for sporadic acute VVC (Guzel et al., 2011). In addition, some studies found an increased incidence of asymptomatic vaginal colonization by Candida after an antibiotic treatment than before it (37\% versus $18-21 \%$ ), and a subsequent development of VVC after the antibiotic intake in $20-22 \%$ of initially colonized women (Pirotta \& Garland, 2006; Xu et al., 2008). These studies also report that only women already colonized with Candida are at risk of VVC following antibiotic treatment.

It is thought that the association of VVC and antibiotics is due to the fact that antibiotic use leads to the depletion of the vaginal bacterial microflora, which represents the dominant vaginal defense mechanism against Candida (Gibbs, 1987). The vaginal microbiota of healthy premenopausal woman is predominantly populated by Lactobacillus species, the most common of which are $L$. iners, $L$. crispatus, $L$. gasseri, $L$. jenesenii, followed by $L$. acidophilus, $L$. casei, $L$. vaginalis, $L$. salivarius (Auger \& Joly, 1980; Cribby et al., 2008; Eschenbach, 1986). In fact, lactobacilli are thought to be involved in several defense mechanisms against Candida. One proposed mechanism is that Lactobacillus species compete with Candida species for nutrients; however, a "shoulder-to- shoulder" survival for lactobacilli and Candida has been shown on an experimental basis, proving that this is not the most effective mechanism (Savage, 1969). More importantly, lactobacilli compete with Candida cells for adhesion sites, such as epithelial receptors, to which Lactobacillus has higher affinity (Boris \& Barbés, 1998, 2000). Some studies have found a decreased adhesion of C. albicans to vaginal epithelial cells when Lactobacillus is present in comparison with the adhesion observed when only Candida is present (Boris \& Barbés, 1998). Furthermore, lactobacilli secrete biosurfactants that physically decrease Candida binding. Velraeds et al. (1998) found a 50\% decrease in the adhesion of $C$. albicans to a silicone rubber filled with a biosurfactant (surlactin) compared with the adhesion levels on silicone rubber without surlactin. Additionally, Okkers et al. (1999) showed that a bacteriocin-like peptide (pentocin TV35b) isolated from Lactobacillus pentosus inhibits C. albicans growth. Moreover, most Lactobacillus strains release hydrogen peroxide $\left(\mathrm{H}_{2} \mathrm{O}_{2}\right)$ and fatty acids that inhibit Candida overgrowth and invasive hypal formation (Boris \& Barbés, 2000). Hillier et al. (2010) showed that women colonized by $\mathrm{H}_{2} \mathrm{O}_{2}$-producing Lactobacillus, are less likely to have symptomatic VVC than women with non- $\mathrm{H}_{2} \mathrm{O}_{2}$-producing Lactobacillus. In addition, Xu and Sobel (2003) showed that L. delbrueckii strains, which produce the largest amounts of $\mathrm{H}_{2} \mathrm{O}_{2}$, have the strongest and fastest growth inhibition effect against $C$. albicans, amongst several Lactobacillus strains isolated from vaginas of healthy women. Moreover, it has been detected higher vaginal $\mathrm{pH}$ in women with $C$. glabrata infection than in those with VVC due to C. albicans (Ahmad $\&$ Khan, 2009; Tarry et al., 2005). In fact, a more alkaline $\mathrm{pH}$ occurs with concomitant bacterial vaginosis has been postulated as a risk factor for $C$. glabrata vaginal infections (Fidel et al., 1999b). In addition, increased vaginal $\mathrm{pH}$ and predominance of NCAC species, especially $C$. glabrata, has been detected in postmenopausal women (Fan et al., 2008b; Holland et al., 2003). Thus, the fact that Candida organisms can adapt to different pHs, makes them important human pathogens. In C. albicans, pH-regulated genes such as PHRI and $P H R 2$ have been identified. $P H R I$ is only expressed at $\mathrm{pH}$ levels above 5.5 and its functional homolog $P H R 2$ is highly expressed when $\mathrm{pH}$ levels are below 5 and is not expressed with $\mathrm{pH}$ above 6 (Muhlschlegel \& Fonzi, 1997). Studies in vitro found that both genes encode a function required for C. albicans morphogenesis. Deletion of PHRI result in 
Figure 5. Scanning electron microscopy images of $C$. tropicalis ATCC biofilms formed at $\mathrm{pH} 4$ (A), $\mathrm{pH} 7$ (B) and $\mathrm{pH} 8$ (C). Original magnification was $\times 1000$ and the scale bars correspond to $20 \mu \mathrm{m}$.
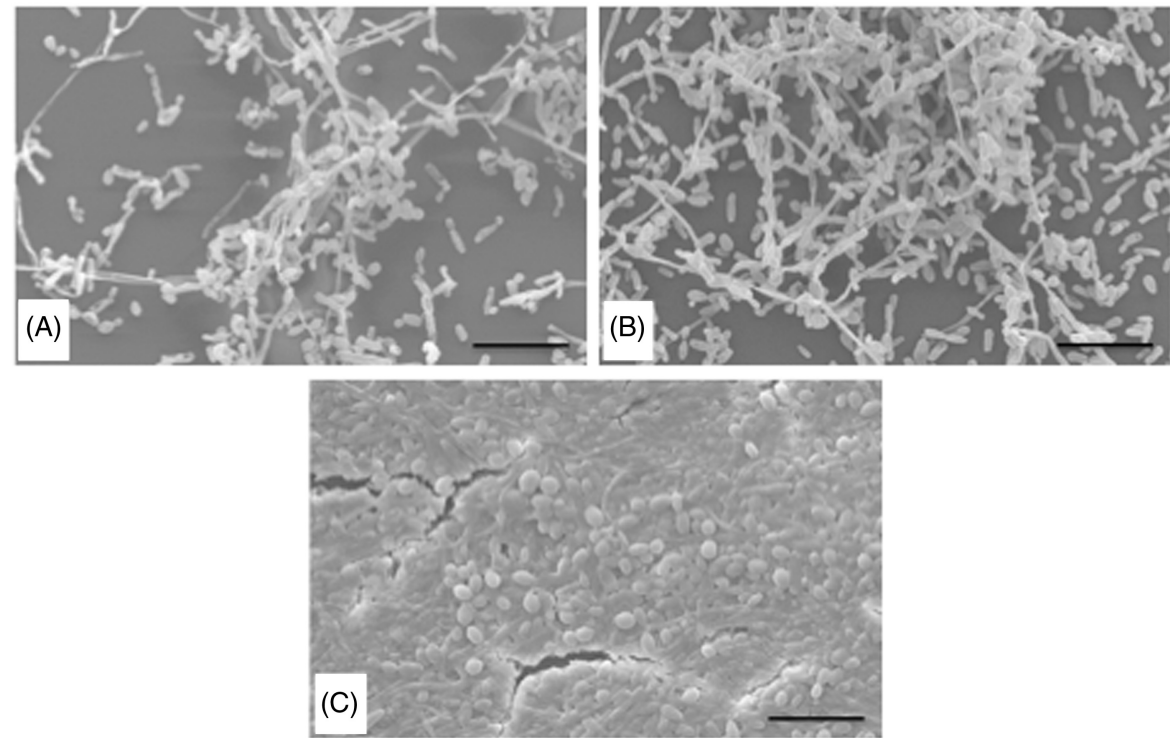

inability to form normal yeast or hyphal morphology at an alkaline $\mathrm{pH}$, but not at an acidic $\mathrm{pH}$, and these mutants lost the ability to cause systemic disease but are fully capable of causing vaginal infection. Conversely, deletion of $P H R 2$ result in a morphogenic defect at an acidic $\mathrm{pH}$ and these mutants lost the ability to cause vaginal infection but are virulent in systemic infections. Besides the morphogenic defect, both mutants also exhibit altered growth rates at the restrictive $\mathrm{pH}$ (De Bernardis et al., 1998; Muhlschlegel \& Fonzi, 1997). In addition, our research group (results unpublished) studied planktonic cultures of C. albicans, C. glabrata, C. parapsilosis and C. tropicalis grown at $\mathrm{pHs}$ between 3 and 8, and we found that these species can proliferate in all tested pHs. We also studied the influence of $\mathrm{pH}$ on the capacity of $C$. tropicalis isolates to form biofilms and we found that the $\mathrm{pH}$ increase lead to an increased biofilm formation capacity (Figure 5) and increased hyphal length, suggesting that Candida species are able to adapt to vaginal environmental $\mathrm{pH}$ alterations.

\section{Immunosuppression}

All Candida infections are dependent on the host, and therefore its immune response is crucial in the host-pathogen interaction (Richardson \& Rautemaa, 2009). In the vaginal environment effective anti-Candida defense mechanisms prevent Candida infection, but allow long-term colonization of Candida organisms as vaginal commensals (Sobel, 2007). Thus, immunosuppressive conditions such as HIV-infection (Nwadioha et al., 2010; Duerr et al., 2003), cancer chemotherapy, glucocorticoids therapy (Zitvogel et al., 2008), organ transplant, cancer, diabetes mellitus, tuberculosis (Nwadioha et al., 2010), and any chronic debilitating illness can increase the chances of developing VVC. Furthermore, it has been proposed that some women with RVVC may have a dysfunction in the normal protective immune response, acquired from early exposure to Candida organisms (Fidel \& Sobel, 1996; Witkin, 1991).

The most studied immunosuppressive condition predisposing to VVC is the HIV infection probably because
VVC may also increase the risk of HIV acquisition (Mostad et al., 1997; Røttingen et al., 2001). It is though that up to $50-70 \%$ of HIV-infected patients develops VVC (Ferrer, 2000). Some studies have reported increased odds for vaginal Candida colonization (Schuman et al., 1998) and symptomatic VVC (Apalata et al., 2014; Duerr et al., 2003) in HIV-infected women than in HIV-negative patients. Moreover, Apalata et al. (2014) found a negative association between the use of highly active antiretroviral therapy and the presence of symptomatic VVC in HIV-infected women. In addition, NCAC species have been found more frequently in HIV-infected women than in non-infected patients (Corsello et al., 2003; Spinillo et al., 1997b). Nevertheless, no studies indicate that HIV-infected women with VVC are less likely to respond to the antifungal therapy or have a more severe fungal infection than HIV-negative women (Duerr et al., 2003; Schuman et al., 1997).

Cells of host's innate immunity express receptors that recognize pathogen associated molecular patterns (PAMPs) found in groups of microorganisms (Medzhitov, 2001). Some of these receptors recognize molecular patterns common to all fungi, while others bind to specific Candida components (Brown \& Gordon, 2005; Jouault et al., 2006). The main classes of pattern recognition receptors that recognize Candida are toll-like receptors (TLR) and lectin-like receptors (LR) families (Netea et al., 2008). In addition to cellmembrane receptors, the circulating mannose binding lectin (MBL) recognizes and binds strongly to Candida surface mannans, enhancing complement activation and thus inhibiting Candida growth (Ip \& Lau, 2004; Pellis et al., 2005). Genetic polymorphisms in recognition receptors such as dectin-1 (Ferwerda, 2009) and MBL (Babula et al., 2003; Giraldo et al., 2007) have been associated with increased susceptibility to RVVC. The cells involved in innate immune system that express cell-membrane receptors include macrophages, dendritic cells (DCs), natural killer (NK), neutrophils and epithelial cells (ECs) (Wira et al., 2005a). The role of neutrophils in anti-Candida protection at the vaginal level is controversial (Fidel et al., 1999a; Fulurija et al., 1996). However, macrophages, DCs and ECs are believed to play 
important protective roles against VVC. Dendritic cells are scattered throughout different portions of the vagina and cervical epithelia, bind to Candida organisms and transmit differentiation and activation signals leading to inflammation, cell activation and induction of adaptive immunity (Liu, 2001). Regarding macrophages, their stimulation through Candida recognition has been shown to induce the synthesis of NO and oxygen radicals, compounds toxic for Candida organisms. Rosentul et al. (2009) detected lower NO concentrations in vaginal secretions of patients with RVVC than of healthy patients. Furthermore, macrophages and DCs contain cell surface receptors that recognize and bind MBL, promoting opsonization of MBL-bounded microorganisms (Babovic-Vuksanovic et al., 1999). In addition, vaginal ECs have been suggested to play a crucial role in the defense mechanisms against VVC (Barousse et al., 2005; Wira et al., 2005b). Vaginal ECs secrete immune mediators such as chemokines and cytokines, which recruit and activate immune cells of both the innate and adaptive immune systems (Cremel, 2005; Wira et al., 2005a). In addition, they also secrete molecules with potent antimicrobial activity such as human $\alpha$-defensin-5 (HD5), $\beta$-defensins 1-4 (HBD14 ), elafin and SLPI (secretory leukocyte protease inhibitor) (King et al., 2000, 2003; Quayle et al., 1998). These antimicrobial peptides have been shown to be effective at inhibiting several pathogens including Candida organisms (Ganz, 2003; Wira et al., 2010); however, a definite antiCandida role for any specific peptide in the vaginal environment has not been established.

The adaptive immunity encompasses fungal-specific defence mechanisms including destruction of specific pathogens directly or indirectly by $\mathrm{T}$ cells (cell-mediated immunity) and protection through specific antibodies produced by B cells (humoral immunity) (Wira et al., 2005a). Depressed T-cell mediated immunity has been suggested to be associated with increased susceptibility to VVC in women with HIV-infection, transplanted organ, under glucocorticoids therapy and cancer chemotherapy (Apalata et al., 2014; Nwadioha et al., 2010; Zitvogel et al., 2008). It has been suggested that most vaginal Tcells migrate to the vaginal epithelium in response to local antigenic stimulation and/or inflammatory chemokines (Cassone et al., 2007; Pudney et al., 2005). It is though that the vaginal mucosa is an immunocompetent tissue capable of a compartmentalized cell-mediated response independent of systemic cell-mediated immunity (Fidel, 2005; Fidel et al., 1996). Some studies have shown that Th1 production of proinflammatory cytokines such as interferon- $\gamma$, may contribute to VVC protection (Carvalho et al., 2002; Kalo-Klein \& Witkin, 1990). However, the protective role of Th1 cells against VVC is still controversial (Fidel et al., 1995, 1999a). In contrast to Th1 cells, Th2 cells produce anti-inflammatory cytokines such as IL-4, which inhibits macrophage-mediated anti-Candida responses and protective pro-inflammatory Th1-derived cytokines (Cenci et al., 1993; Essner et al., 1989). Rosentul et al. (2009) showed that a genetic propensity to an overwhelming release of anti-inflammatory Th2-derived cytokines contributes to RVVC development. In addition, Pietrella et al. (2011) showed that Th17 cells (which belong to a different lineage from that of Th1 and Th2) and the IL-17 production by them have an important role in the immune response to VVC. Similar to T cells, B cells and immunoglobulin (Ig)-secreting plasma cells, migrate to the vaginal epithelium where they are normally absent, in response to an antigenic stimulation (Fidel \& Sobel, 1996; Pudney et al., 2005). The local production of antibodies by these cells might be a quick mechanism for combating pathogenic microorganisms without the need to wait for the beginning of the systemic immune response. The exact mechanism by which antibodies may protect against Candida infections is unknown, but appears to include inhibition of adhesion, opsonization, neutralization of enzymes related to virulence and direct fungicidal activity (Moragues et al., 2003; Russell \& Mestecky, 2002).

Immunoglobulin A ( $\operatorname{IgA})$ and $\operatorname{IgG}$ are the predominant $\operatorname{Ig}$ classes found in vaginal secretions, suggesting that they represent the dominant Igs in the female lower genital tract (Carvalho et al., 2003; Parr \& Parr, 1994). Carvalho et al. (2003) found a marked response of $\mathrm{IgA}, \mathrm{IgG1}$ and $\mathrm{IgG} 4$ in vaginal washes of symptomatic women with VVC comparatively to symptomatic women without Candida, suggesting that the synthesis of those antibodies was stimulated by the presence of the fungus. In fact, several studies have shown that vaginal colonization or infection by Candida induces antiCandida antibodies production (Carvalho et al., 2003; Fidel \& Sobel, 1996; Silva et al., 2008), but whether these humoral responses are important for avoid VVC is still controversial. Some studies have reported normal or high titers of Candidaspecific antibodies in vaginal secretions of women with VVC and RVVC, suggesting little to no protective role for antibodies (Fidel et al., 1997; Fidel, 2005). In contrast, other studies found low levels of anti-Candida antibodies in vaginal washes of women with VVC than of healthy colonized patients, proposing that the decrease of antibody levels promoted Candida infection (Gough et al., 1984; Silva et al., 2008). Moreover, it has been also shown that the secretor component of IgA can attach to $C$. albicans in a nonimmune way, blocking Candida binding to cellular receptors (Silva et al., 2008). This immunoglobulin forms complexes with Candida organisms, which are removed by the secretion of mucin, thus contributing to the inhibition of Candida adhesion to the vaginal epithelium (Russell \& Mestecky, 2002; Silva et al., 2008). Nevertheless, vaginal secretory immunity can also be the cause of higher susceptibility to VVC. It has been proposed that some women could have IgE-mediated hypersensitivity contributing to the etiology and/or severity of the infection. High levels of $\operatorname{IgE}$ have been found in vaginal secretions of women with VVC and particularly with RVVC, compared to healthy women, suggesting an allergic sensitization to Candida antigens (Fan et al., 2008a; Regúlez et al., 1994; Witkin et al., 1989). In addition, hypersensitivity reactions have been also associated with eosinophils and prostaglandin E2, which are also found in higher levels in vaginal secretions of women with RVVC than of patients without RVVC (Fan et al., 2008a; Weissenbacher et al., 2009).

\section{Uncontrolled diabetes and glucocorticoids}

Diabetes mellitus (DM) has been proposed as a risk factor for the development of VVC since higher prevalence of VVC 
has been found in diabetic women than in nondiabetics. The incidence of VVC in diabetic women ranges between 32 and $67.5 \%$ and in non-diabetic patients ranges between $11 \%$ and 23\% (Goswami et al., 2000, 2006; Grigoriou et al., 2006). Furthermore, higher vaginal colonization by Candida and higher development of RVVC has been detected in diabetic patients than in non-diabetics (Bohannon, 1998; Gunther et al., 2014). It has also been shown that, a large proportion of VVC in diabetic women is due to NCAC species, especially C. glabrata. This species has been isolated in $50-61 \%$ of diabetic patients with $\mathrm{VVC}$, whereas $C$. albicans is only detected in 29-36\% of these women (Goswami et al., 2006; Peer et al., 1993; Ray et al., 2007). In addition, De Leon et al. (2002) found that most diabetic type 1 participants were vaginal colonized with $C$. albicans $(56 \%)$, while $C$. glabrata was the most common isolate among type 2 participants (54\%). High predominance of NCAC species in diabetic women may have important implications for VVC treatment because NCAC species are inherently less susceptible to conventional antifungal therapy. In fact, Goswami et al. (2006) reported that $81.3 \%$ of diabetic patients with VVC continued to show fungal growth following fluconazole therapy, when $C$. glabrata was the organism grown and only $45.4 \%$ of patients had persistent $C$. albicans infection. Furthermore, these investigators also found that Candida persistence was higher in diabetic women than in the nondiabetics control group $(78.6 \%$ and $21.5 \%$ for C. glabrata and C. albicans, respectively. It has been proposed that elevated levels of glucose predispose to VVC by impairing basic mechanisms of host defense and by promoting Candida adhesion to vaginal cells (Hostetter, 1990). Studies in vitro have shown that vaginal epithelial cells from diabetic women have an enhanced capacity to bind to $C$. albicans than vaginal cells from non-diabetic patients (Kalo \& Segal, 1988; Segal et al., 1984). It is though that the excess of glucose increases the nutritive substract of Candida microorganisms, promoting their adhesion (Pereira et al., 1996). Furthermore, it is supposed that an isomer of glucose, a fucose (6-deoxy galactose) vaginal epithelial cell receptor, helps Candida adhesion to vaginal epithelial cells (Sobel et al., 1981). More importantly, C. albicans expresses a glucose-inducible surface protein that promotes its adhesion to vaginal epithelial cells (Hostetter, 1990). Some studies have shown that the expression of this protein is increased four- to six fold when the concentration of glucose in the growth medium is raised from 5 to $50 \mathrm{mM}$ (Gilmore et al., 1988; Hostetter et al., 1990). Moreover, this protein is structurally and functionally homologous to a complement receptor on mammalian phagocytes and its increase impairs neutrophil phagocytic recognition (Gilmore et al., 1988). Furthermore, glucose binds covalently and irreversibly to the complement C3 inhibiting the attachment of this protein to Candida microorganisms, which is the critical determinant of phagocytic recognition (Hostetter, 1990). In addition, it has been also shown that neutrophils of diabetics are less effective than those of healthy patients in killing C. albicans (Wilson \& Reeves, 1986). It is suggested that the inhibition of $C$. albicans killing by neutrophils in diabetic patients is due to a competition between oxidative killing and sorbitol production, for the electron donor NADPH (Wilson et al., 1987). This supposition was based on the fact that increased concentration of glucose leads to decreased oxidative killing of $C$. albicans by neutrophils and increased presence of sorbitol (Wilson et al., 1987). In fact, it has been found that hyperglycemic environment inhibits several neutrophil functions such as phagocytosis, adhesion, chemotaxis and intracellular killing (Bohannon, 1998). Most of mechanisms responsible for these dysfunctions are not clear but they can be corrected or at least substantially improved with control of plasma glucose (Bohannon, 1998).

In addition, the use of glucocorticoids has been proposed as a risk factor for VVC (Sobel, 2007). Glucocorticoids are used to treat several human illnesses, such as, autoimmune diseases and cancer and to prevent rejection following organ transplant. However, one of their many undesirable side effects is hyperglycemia caused by increased production of glucose from amino-acids breakdown and resistance to the insulin action (Ferris \& Kahn, 2012). Thus, it can be suggested that the high blood glucose levels that contribute for VVC in diabetic patients, have similar action on glucocorticoids users, leading to an increased risk of VVC development. Furthermore, it was shown that several Candida species possess a corticosteroid-binding protein and synthesize a fungal ligand that competes with corticosteroids for mammalian glucocorticoid receptors, leading to the speculation that exogenous glucocorticoids may directly mediate Candida virulence (Hostetter, 1990). In addition, the use of glucocorticoids suppress several immune reactions (which is one of the main reasons for their use), increasing the vulnerability to fungal infections (Barnes, 2011). Although the incidence of VVC in patients with glucocorticoids therapy is unknown, it has been shown that their use increases the incidence of other Candida infections, for instance oral candidiasis (Fukushima et al., 2003).

\section{Genetic predispositions}

Since many women develop VVC without any known predisposing factor, some groups of researchers have turned to genetic studies to reveal a possible association of VVC with genetic predispositions (Bradford et al., 2013). American studies have found that African-American women have increased prevalence of VVC (Geiger \& Foxman, 1996) and are more likely to be vaginal colonized by Candida (Cotch, 1998) compared to Hispanic and white women. Furthermore, black women have decreased vaginal $\mathrm{H}_{2} \mathrm{O}_{2}$-producing Lactobacillus population, which is a protective barrier against Candida microorganisms (Antonio et al., 1999). Thus, a genetic-related predisposition has been proposed as a risk factor for VVC in black women. Another genetic predisposition may be a polymorphism in Lewis blood group antigens that leads to the blood group ABO-Lewis non-secretor phenotype. This status is detected with increased frequency among women with RVVC (Chaim et al., 1997; Hilton et al., 1995).

Genetic polymorphisms in innate immunity genes have been also associated with increased susceptibility to VVC and especially to RVVC, including polymorphisms in mannosebinding Lectin (MBL) gene, dectin-1 stop-codon, Interleukin4 (IL-4) gene and NLRP3 gene (Rosentul et al., 2009). Candida components are initially recognized by the innate 
immune system through recognition receptors, among which dectin-1 and MBL. Dectin-1 is a C-type lectin receptor expressed on the cell-membrane of innate immune cells, that amplifies TLR-induced cytokine production (e.g. IL-17, IL-6 and IL-10) (Gow et al., 2007). It was detected a mutation in an early stop-codon of dectin-1 gene that leads to the loss of the last nine amicoacids of the CDR (carbohydrate recognition domain). This mutation results in the loss of $\beta$-glucan recognition and impaired cytokine response, particularly of pro-inflammatory cytokine IL-17 (Brown, 2006). This mutation has been described in a family of patients with RVVC and onycomycosis (Ferwerda, 2009) and seems to have no correlation with susceptibility to systemic candidiasis (Plantinga et al., 2009). Regarding MBL, it is a circulating protein that binds strongly mannose and $\mathrm{N}$-acetyl-glucosamine residues on the surface of Candida microorganisms, activating the complement system and promoting opsonization (Neth et al., 2000). Reduced levels of MBL and increased occurrence of genetic polymorphisms in the MBL gene were found in Chinese and Latvian women with RVVC (Babula et al., 2003; Giraldo et al., 2007; Liu et al., 2006).The decrease in circulating MBL concentrations has been shown to correlate with mutations in exon 1 of MBL gene, specially the substitution of an adenine for a guanine in codon 54, which results in impaired assembly and stability of the final MBL protein (Babula et al., 2003; Lipscombe et al., 1995; Sumiya et al., 1991). The stimulation of Candida recognition receptors induces the production of several cytokines, among which the anti-inflammatory IL-4 and the pro-inflammatory Interleukin-1 $\beta$ (IL-1 $\beta$ ). IL-4 inhibits anti-Candida activity of Nitric Oxide (NO), which is an important effector molecule of the innate immune defense against Candida (Cenci et al., 1993). Thus, high production capacity of IL-4 is associated with immunosuppressive effects. It has been shown that a polymorphism in the promoter region of the IL-4 gene, consisting of a cytosine to thymine variation (C589T), leads to an increased production of IL-4 by immune cells (Burchard et al., 1999; Rosenwasser et al., 1995). The occurrence of this IL-4 gene polymorphism has been correlated with high prevalence of RVVC in some studies (Babula et al., 2005; Liu et al., 2006). Furthermore, higher concentrations of vaginal IL-4 and lower vaginal NO concentrations has been reported in patients with RVVC than in healthy women (Rosentul et al., 2009). Regarding IL-1 $\beta$, this cytokine is processed and activated by a complex called inflammasome, which contains the NLR receptors NLRP3, ASC and caspase-1 (Rosentul et al., 2009). Polymorphisms of the NRLP3 gene have been described and seem to have a possibly relationship with RVVC, however this potential association has not been completely clarified (Lev-Sagie et al., 2009).

\section{Behavioral factors}

\section{Oral contraceptive pills}

The use of oral contraceptive pills (OCP) has been proposed as a risk factor for VVC by some authors. However, the recognition of this contraceptive method as a risk factor is still controversial because epidemiologic data are contradictory. In fact, some studies reported higher incidence of VVC (39-58\% versus 20-38\%) (Cetin et al., 2007; Egbe et al., 2011; Neerja et al., 2006) and vaginal colonization by Candida (58-69\% versus 35-40\%) (Apalata et al., 2014; Oviasogie \& Okungbowa, 2009), in women taking OCP than in patients not using this method. However, other investigators did not found an association between OCP use and vaginal colonization or presence of VVC (Andrioli et al., 2009; Reed et al., 2000; Sobel et al., 2004). Nevertheless, some authors report that although they have not found increased sporadic VVC in women taking OCP, they found and increased prevalence of RVVC in these women, especially in long time OCP users, proposing the use of OCP as a predisposing factor for RVVC (Rylander et al., 2004; Spinillo et al., 1993, 1995).

The use of OCP causes anovulation, with the subsequent absence of estrogen and progesterone peaks, usually present in the normal menstrual cycle. However, OCP add constant levels of hormones that act in the host and Candida microorganisms, possibly contributing to VVC. Almost all OCP are combinations of synthetic estrogens and progestins. The most used estrogens are ethinyl estradiol and mestranol and the most used synthetic progestins are norethindrone, norethynodrel, etynodiol and norgestrel (Guyton \& Hall, 2006). Some authors believe that hormonal effects that contribute to VVC in pregnancy are similar to those that act in women taking OCP, especially OCP containing a high hormonal dose (Bauters et al., 2002). Thus, the use of OCP may increase vaginal glycogen consequently increasing the availability of nutrient carbohydrates that support Candida growth (Reed, 1992). Moreover, OCP use may also increase Candida adhesion to vaginal epithelium by Candida hormone-receptors stimulation and hyphal forms induction (Cheng et al., 2006; Reed, 1992). In fact, Cheng et al. (2006) detected a similar effect of synthetic ethinyl estradiol and human $\beta$-estradiol on the increase of $C$. albicans hyphal forms. Furthermore, OCP use may also influence immune responses resulting in decreased vaginal resistance to Candida. Levels of lactoferrin and immunoglobulins (IgA and $\operatorname{IgG}$ ) have been shown to be suppressed in women taking OCP for the duration of hormone exposure (Fleetwood et al., 1984). In addition, a study with women taking injectable hormonal contraceptives (DMPA - depot medroxyprogesterone acetate) found that this hormonal contraception compromises the vaginal barrier to infection (Miller et al., 2000). The hormonal dependency of VVC is well accepted in pregnancy however there is not a consensual acceptation that OCP use is a risk factor for VVC.

\section{Intrauterine device}

The use of intrauterine device (IUD) is a highly effective, safe and economic contraception method (Demirezen et al., 2005). It is a very popular way of preventing pregnancy used by millions of women worldwide and the most preferred mean of contraception in women of developing countries (Abasiattai et al., 2008; Lal et al., 2008). The IUDs are available in several shapes and sizes and are made up of a variety of materials ranging from copper to all plastic (Pruthi et al., 2003). The insertion of an IUD stimulates foreign body response or inflammatory reaction, which cause cellular/ biochemical alterations in the endometrial mucosa and cervical mucus, leading to the contraceptive effects 
(Lal et al., 2008; Pruthi et al., 2003). IUDs that constantly release small amounts of hormones into the uterus are also available (Lal et al., 2008; Pruthi et al., 2003). Despite being effective in preventing fertilization, some studies have shown that IUD use increases the risk of complications such as pelvic inflammations and menstrual cramps (Pruthi et al., 2003; Lee et al., 1983). More importantly, IUDs use also increases the risk of infections associated with microbes' colonization on these implanted devices, including VVC (Lal et al., 2008; Pruthi et al., 2003). Although some researchers have not found an association between VVC and IUD use (Agarwal et al., 2004; Hodoglugil et al., 2000), it has been proposed as an important risk factor for sporadic VVC and recurrent episodes by many others. In fact, several studies report higher IUD use in VVC and RVVC-infected women (13.1-43.8\% and $28.1-71.4 \%$, respectively) than in healthy women (2.9-37.6\%) (Amouri et al., 2011; Guzel et al., 2011; Spinillo et al., 1995). In addition, some studies also found that VVC incidence and vaginal colonization by Candida is higher among IUD users than in non-users (Apalata et al., 2014; Cetin et al., 2007; Demirezen et al., 2005).

It has been suggested that the association of IUD use with VVC episodes is due to the Candida adhesion and biofilm formation on the surface of the device (Auler et al., 2010; Chassot et al., 2008). A biofilm is a surface-associated community of microorganisms enclosed in a self-produced matrix that confers resistance to antifungal agents, host defenses and stress (Donlan \& Costerton, 2002). Pathogenic fungi can form biofilms on the inert surfaces of several implanted devices, including catheters, prosthetic cardiac valves and IUDs (Douglas, 2003; Pruthi et al., 2003). Chassot et al. (2008) showed that $C$. albicans isolates of patients with VVC can adhere strongly in vitro to all parts of an IUD and have high capacity to form biofilm on it. Moreover, these investigators detected high concentration of yeasts on the IUD tail, which is the segment that makes a bridge between external environment, the vagina that is colonized by yeasts and the non-colonized upper genital tract. The presence of a biofilm on the surface of IUD not only protects yeasts from the action of antifungal agents as it contributes to the microorganism's persistence, constituting a source of infection or reinfection (Auler et al., 2010; Pál et al., 2005). Some studies have shown that IUDs recovered from patients suffering from VVC or RVVC are infected by Candida biofilms composed of a single or multiple species (including bacteria), indicating that the presence of the biofilms on the device possibly contributed to the infection (Auler et al., 2010; Lal et al., 2008; Pruthi et al., 2003). Furthermore, Auler et al. (2010) verified through electron scanning microscopy that most microorganisms of biofilms formed on IUDs of patients with RVVC had been present on those surfaces for possibly a long time, suggesting that biofilms served as reservoirs of yeasts. These investigators also observed a larger mass of biofilm on the device of the patient with its longer use. Pál et al. (2005) also reported that biofilm formation on IUDs has a relation to duration of use and Demirezen et al. (2005) showed that women with less than 1 year of IUD use have decreased risk of developing device-related VVC. Besides acting as a Candida reservoir, it is also proposed that IUDs may affect the cervico-vaginal microflora by reducing lactobacilli, an important vaginal barrier against Candida organisms (Demirezen et al., 2005). Furthermore, the use of IUD may predispose the cervico-flora for the more pathogenic Candida hyphae form and modifies or destroys the cervical mucus, which serves as a powerful barrier for ascending infections (Demirezen et al., 2005).

The association of IUD use with infections as VVC has led several authors to suggest a controlled and limited use of the IUD and a regular check of possible infections during its usage to prevent serious complications (Auler et al., 2010; Demirezen et al., 2005; Guzel et al., 2011). The IUD removal is required in many infected patients, especially in women with RVVC, in which the removal of the device has been shown to be essential to avoid the relapses (Auler et al., 2010; Parewijck et al., 1988).

\section{Spermicides/condoms}

The use of spermicides and/or condom has been associated with increased risk of VVC by some authors. Some epidemiologic data report higher incidence of VVC in condom users $(40.2 \%)$ than in non-contraceptive users (37.9\%) (Cetin et al., 2007) and higher use of spermicides in patients with VVC (56.3\%) than in healthy women (13.5\%) (Geiger \& Foxman, 1996). Furthermore, it has been reported higher use of spermicide and/or condom in RVVC patients than in healthy women (21.4\% versus 10\%) (Amouri et al., 2011) and higher condom use in patients colonized by Candida than in non-colonized women (11\% versus $5 \%)$ (Eckert, 1998).

It is proposed that the association between spermicides/ condoms and VVC development may due to the spermicidal compound nonoxynol-9 (N9), which is the active component of many spermicidal preparations used in spermicides (creams and foams) and condoms (McGroarty et al., 1990). N-9 is a nonionic detergent that immobilizes sperm by disrupting the cell membrane and acts similarly on several pathogens, mainly bacteria and viruses, decreasing the risk of acquiring several sexually transmitted diseases (North, 1988). However, this compound upsets the ecological balance of vaginal microbiota because it also inhibits vaginal commensal organisms, specifically Lactobacillus species (Hooton et al., 1994; Watts et al., 1999), which represent the dominant vaginal defense mechanism against Candida. Furthermore, some studies showed that N-9 causes vaginal epithelium disruption, leading to genital irritation (Niruthisard et al., 1991; Roddy et al., 1993). In addition, McGroarty et al. (1990) reported that Candida microorganisms have the ability to metabolize the spermicidal compound N-9, which may result in altered surface characteristics, increasing Candida adhesion to epithelial tissues. These investigators showed that the incorporation of N-9 in adhesion assays with vaginal isolates of C. albicans, C. parapsilosis and C. tropicalis increase their adhesion to human epithelial cells. They proposed that N-9, which is a detergent molecule composed of a polar head and a hydrophobic tail, may enhance the adhesion of Candida organisms by increasing their hydrophobicity or epithelial cells hydrophobicity. In fact, it has been shown that the initial attachment of Candida cells to biotic and abiotic 
surfaces is mediated by Candida surface hydrophobicity (Hazen, 1989) and that hydrophobic Candida cells are more virulent than hydrophilic ones (North, 1988).

Despite the use of N-9 in condoms appear to be the most probable cause of their association with VVC development, other causes have been also proposed such as, allergic reactions to latex, sensitivity of vaginal epithelial cells to condom and vaginal micro traumas with consequent disturbance of the vaginal ecosystem (Giraldo et al., 2005; Schreiber et al., 2006).

\section{Poor personal hygiene and sexual habits}

It is though that an increase in the number of Candida spores in the vaginal environment triggers epithelial invasion possibly contributing to VVC (Ferrer, 2000). Thus, factors that may increase the vaginal blastopore load have been proposed as risk factors for VVC. For instance, an increased Candida spore load can have an intestinal reservoir source due to inappropriate personal hygiene (Ferrer, 2000). An Indian study found higher incidence of VVC in women with unsatisfactory genital hygiene $(36.0 \%)$ than in those with satisfactory personal hygiene (15.6\%) (Ahmad \& Khan, 2009). Furthermore, an Iranian study reported low education degree in $63 \%$ of women with VVC and attributed that result to a possible less observance of genital hygiene in those women (Faraji et al., 2012). In fact, it has been shown that the gut is a possible source of vaginal colonization by Candida microorganisms (Holanda et al., 2007). Although it is thought that intestinal tract has a minor role in VVC (Sobel, 2007), an increase in the number of Candida spores in vagina promoted by poor genital hygiene, possibly contributes to VVC. However the association between inappropriate intimate hygiene and VVC has to be further studied.

In addition to poor personal hygiene, an increase in Candida blastopore load can be also due to exogenous Candida acquisition through some sexual practices, including frequent sexual intercourse and receptive orogenital intercourse. These sexual behaviors may be of importance for both primary infection and recurrent VVC episodes. Some studies have found a correlation between high frequency of monthly intercourse and vaginal Candida colonization (Eckert, 1998), VVC development (Foxman, 1990) and recurrent episodes (Spinillo et al., 1993, 1995). Moreover, several studies have found that VVC occurs more frequently in the third decade of life and have suggested that this may be due to an increased sexual activity in this age group (Ahmad \& Khan, 2009; AkoNai et al., 1993; Okungbowa et al., 2003). VVC is not considered a sexually-transmitted disease because it occurs in non-sexually active women and women can be vaginal colonized by Candida, but nevertheless, some studies have confirmed Candida sexual transmission (Boatto et al., 2007; Schmid et al., 1993). Thus, high frequency of sexual intercourse may lead to an increase of vaginal Candida load, possibly contributing to VVC episodes. However, some authors suggest that Candida penile-vaginal transmission occurs in only a few cases and that, other factors also contribute to increased VVC risk in women with frequent sexual intercourse. These factors include vulvovaginal microlacerations that create conditions suitable for yeast to invade tissue (Foxman, 1990; Hellberg et al., 1995) and exposition to numerous antigens, antibodies and cytokines secreted in the seminal fluid that might influence women immune reaction to Candida (Reed et al., 2000). Furthermore, deposition of semen (alkaline $\mathrm{pH}$ ) in the vaginal epithelium can lead to an alteration of vaginal microbiota, local mucosa stimulation and introduction of strange bacteria to vaginal environment (Giraldo et al., 2005). Besides frequent sexual intercourse, also receptive oral intercourse has been proposed as a risk factor of both sporadic and recurrent VVC infections. In fact, some studies have found that orogenital sex is associated with increased VVC incidence (Bradshaw et al., 2005; Reed et al., 2000; Rylander et al., 2004) and with repeated episodes of VVC (Hellberg et al., 1995; Markos et al., 1992; Reed et al., 2003). It has been shown that Candida organisms can be transmitted from the oral cavity (Reed et al., 2000), in which they are present in one-third to one-half of adult population, leading to increased vaginal load. It has been also proposed that saliva may facilitate Candida adherence and growth through moistening and irritation of the vaginal mucosa (Geiger \& Foxman, 1996; Reed et al., 2000) or by changing the local immune responses (Reed et al., 2000).

Other sexual practices such as receptive anal sex (Bradshaw et al., 2005; Hellberg et al., 1995), early sexual debut, casual sex partners (Hellberg et al., 1995), new sex partner (Spinillo et al., 1993), high number of lifetime sex partners (Spinillo et al., 1995) and sex during menses (Hellberg et al., 1995) have been also positively associated with VVC episodes by some studies, especially in patients with RVVC. However some researchers have not found increased risk of infection in women with some of these sexual behaviors (Barbone et al., 1990; Foxman, 1990; Reed et al., 2000). Thus, the influence of these and other sexual habits needs to be further studied for a better understanding of their role in VVC development.

\section{Habits of clothing and hygiene}

Some habits of feminine hygiene and clothing have been proposed as potential behavioral factors that predispose to VVC and RVVC. The use of tight or poorly ventilated clothing and/or use of synthetic underwear have been associated with VVC development by some authors. A Brazilian study found higher incidence of VVC in women who use tight and/or synthetic underwear $(65.8 \%)$ than in women who not use those type of clothing (39.1\%) (Holanda et al., 2007). Furthermore, an Italian study found a more common use of synthetic underwear in RVVC patients (36.8\%) than in patients with no recent history of VVC (26.0\%) (Corsello et al., 2003). In addition, an American study with RVVC-infected patients found that women who used pantyhose were more than twice as likely to report an episode of VVC during the study period, than women who not used that tight-fitting garment $(40.1 \%$ versus $16.6 \%)$ (Patel et al., 2004). Thus, some authors propose that the use of well-ventilated and cotton underwear could be of value in preventing VVC; however, not all researches found an association between the use of tight clothing or synthetic underwear and VVC development (Foxman, 1990; Patel et al., 2004). 
The possible association between poorly ventilated clothing and/or synthetic underwear and VVC has been attributed to increased perineal moisture levels and temperature which may contribute to Candida proliferation (Sobel, 2014). It has also been suggested that synthetic underwear may cause local allergy and hypersensitivity reactions, altering the vaginal milieu and possibly contributing to VVC (Neves et al., 2005). In fact, feminine hygiene practices that may trigger local hypersensitivity or allergic reactions as the use of pantyliners and vaginal douching have been also proposed as behavioral risk factors for VVC development. Patel et al. (2004) found higher incidence of VVC in patients that use pantyliners than in women who not use them (46.6 versus $14.3 \%$ ). Barousse et al. (2004) found higher vaginal colonization by Candida in women that use solutions for vaginal douching (26\%) than in women who not have this habit (20\%). Furthermore, some studies found that vaginal douching is more common among VVC and RVVC patients than in healthy women (Bradshaw et al., 2005; Corsello et al., 2003; Spinillo et al., 1993). It is believed that vaginal douching not only introduces exogenous substances that may cause allergic reactions and $\mathrm{pH}$ alteration, but also promote mechanical cleaning of commensal bacteria, affecting the ecological balance of the vaginal cavity (Ness et al., 2003). In addition, it has been recommend for women to avoid excessive washing of vulval area and potential irritants such as perfumed soaps, bubble baths, powders or vaginal sprays, which also affect the vaginal microbiota (Watson \& Calabretto, 2007).

\section{Conclusion}

Changes in the vaginal environment are generally required for the alteration of the opportunistic Candida organisms from commensal to pathogenic. Management of VVC involves the identification and control of risk factors that may predispose to infection. Having a risk factor for VVC increases the chance of getting the infection, but does not always lead to it. Also, the absence of any known risk factor does not necessarily avoid VVC development. Despite research advances, there are still a number of mechanisms involved in VVC and RVVC development that need to be clarified. Thus, the high incidence of VVC, it negatives consequences and the increase of antifungal failure in its treatment, make it crucial to further increase our knowledge on Candida vaginal pathogenicity and its underlying mechanisms. Studies in this area will lead to a better understand of VVC, contributing to the identification of new targets for more efficient therapeutic approaches against this clinically relevant fungal infection.

\section{Declaration of interest}

The authors report no declarations of interest. This study was supported by the Programa Operacional, Fatores de competitividade - COMPETE and by national funds through FCT Fundação para a Ciência e a Tecnologia on the scope of the projects FCT PTDC/EBB-EBI/120495/2010, RECI/EBBEBI/0179/2012 and PEst-OE/EQB/LA0023/2013. The authors thank the Project "BioHealth - Biotechnology and Bioengineering approaches to improve health quality," Ref. NORTE-07-0124-FEDER-000027, co-funded by the
Programa Operacional Regional do Norte (ON.2 - O Novo Norte), QREN, FEDER.

\section{References}

Abasiattai AM, Bassey EA, Udoma EJ. (2008). Profile of intrauterine contraceptive device acceptors at the University of Uyo Teaching Hospital, Uyo, Nigeria. Ann Afr Med 7:1-5.

Achkar JM, Fries BC. (2010). Candida infections of the genitourinary tract. Clin Microbiol Rev 23:253-73.

Agarwal K, Sharma U, Acharya V. (2004). Microbial and cytopathological study of intrauterine contraceptive device users. Indian J Med Sci 58:394-9.

Ahmad A, Khan AU. (2009). Prevalence of Candida species and potential risk factors for vulvovaginal candidiasis in Aligarh, India Eur J Obstet Gynecol Reprod Biol 144:68-71.

Ako-Nai AK, Kassim OO, Adeniram MO, Taiwo O. (1993). A study of urinary tract infections at Ile-Ife, Nigeria. East Afr Med J 70:10-14

Alves CT, Silva S, Pereira L, et al. (2014a). Effect of progesterone on Candida albicans vaginal pathogenicity. Int J Med Microbiol 304: 1011-17.

Alves CT, Wei XQ, Silva S, et al. (2014b). Candida albicans promotes invasion and colonisation of Candida glabrata in a reconstituted human vaginal epithelium. J Infect 69:396-407.

Amouri I, Sellami H, Borji N, et al. (2011). Epidemiological survey of vulvovaginal candidosis in Sfax, Tunisia. Mycoses 54:499-505.

Anderson J, Cundiff L, Schnars B, et al. (1989). Hypha formation in the white-opaque transition of Candida albicans. Infect Immun 57: 458-67.

Anderson JM, Soll DR. (1987). Unique phenotype of opaque cells in the white-opaque transition of Candida albicans. J Bacteriol 169: 5579-88.

Anderson MR. (2004). Evaluation of vaginal complaints. JAMA 291: 1368-79.

Andrioli JL, Oliveira GSA, Barreto CS, et al. (2009). Frequência de leveduras em fluido vaginal de mulheres com e sem suspeita clínica de candidíase vulvovaginal. Rev Bras Ginecol e Obs 31:300-4.

Antonio MAD, Hawes SE, Hillier SL. (1999). The identification of vaginal Lactobacillus species and the demographic and microbiologic characteristics of women colonized by these species. J Infect Dis 180: 1950-6.

Apalata T, Longo-Mbenza B, Sturm A, et al. (2014). Factors associated with symptomatic vulvovaginal candidiasis: a study among women attending a primary healthcare clinic in Kwazulu-Natal, South Africa. Ann Med Health Sci Res 4:410-16.

Ascioglu S, Rex JH, de Pauw B, et al. (2002). Defining opportunistic invasive fungal infections in immunocompromised patients with cancer and hematopoietic stem cell transplants: an international consensus. Clin Infect Dis 34:7-14.

Auger P, Joly J. (1980). Microbial flora associated with Candida albicans vulvovaginitis. Obstet Gynecol 55:397-401.

Auler ME, Morreira D, Rodrigues FF, et al. (2010). Biofilm formation on intrauterine devices in patients with recurrent vulvovaginal candidiasis. Med Mycol 48:211-16.

Babovic-Vuksanovic D, Snow K, Ten RM. (1999). Mannosebinding lectin (MBL) deficiency. Variant alleles in a midwestern population of the United States. Ann Allergy Asthma Immunol 82: 134-8.

Babula O, Lazdane G, Kroica J, et al. (2005). Frequency of Interleukin-4 (IL-4) -589 gene polymorphism and vaginal concentrations of IL-4, nitric oxide, and mannose-binding lectin in women with recurrent vulvovaginal candidiasis. Clin Infect Dis 40:1258-62.

Babula O, Lazdane G, Kroica J, et al. (2003). Relation between recurrent vulvovaginal candidiasis, vaginal concentrations of mannose-binding lectin, and a mannose-binding lectin gene polymorphism in Latvian women. Clin Infect Dis 37:733-7.

Barbone F, Austin H, Louv WC, Alexander WJ. (1990). A follow-up study of methods of contraception, sexual activity, and rates of trichomoniasis, candidiasis, and bacterial vaginosis. Am J Obstet Gynecol 163:510-14.

Barnes PJ. (2011). Glucocorticosteroids: current and future directions. $\mathrm{Br}$ J Pharmacol 163:29-43. 
Barousse MM, Espinosa T, Dunlap K, Fidel PL. (2005). Vaginal epithelial cell anti-Candida albicans activity is associated with protection against symptomatic vaginal candidiasis. Infect Immun 73:7765-7.

Barousse MM, Van Der Pol BJ, Fortenberry D, et al. (2004). Vaginal yeast colonisation, prevalence of vaginitis, and associated local immunity in adolescents. Sex Transm Infect 80:48-53.

Bauters TG, Dhont MA, Temmerman MI, Nelis HJ. (2002). Prevalence of vulvovaginal candidiasis and susceptibility to fluconazole in women. Am. J Obstet Gynecol 187:569-74.

Beigi RH., Meyn LA, Moore DM, et al. (2004). Vaginal yeast colonization in nonpregnant women: a longitudinal study. Obstet Gynecol 104:926-30.

Bertholf ME, Stafford MJ. (1983). Colonization of Candida albicans in vagina, rectum, and mouth. J Fam Pract 16:919-24.

Bluestein D, Rutledge C, Lumsden L. (1991). Predicting the occurrence of antibiotic-induced candidal vaginitis (AICV). Fam Pract Res J 11: 319-26.

Boatto HF, de Moraes MS, Machado AP, et al. (2007). Correlação entre os resultados laboratoriais e os sinais e sintomas clínicos das pacientes com candidíase vulvovaginal e relevância dos parceiros sexuais na manutenção da infecção em São Paulo, Brasil. Rev Bras Ginecol e Obs 29:80-4.

Bohannon NJV. (1998). Treatment of vulvovaginal candidiasis in patients with diabetes. Diabetes Care 21:451-6.

Boris S, Barbés C. (1998). Adherence of human vaginal lactobacilli to vaginal epithelial cells and interaction with uropathogens. Infect Immun 66:1985-9.

Boris S, Barbés C. (2000). Role played by lactobacilli in controlling the population of vaginal pathogens. Microbes Infect 2:543-6.

Bradford LL, Ravel J, Bruno V. (2013). Understanding vulvovaginal candidiasis through a community genomics approach. Curr Fungal Infect Rep 7:126-31.

Bradshaw CS, Morton AN, Garland SM, et al. (2005). Higherrisk behavioral practices associated with bacterial vaginosis compared with vaginal candidiasis. Obstet Gynecol 106: 105-14.

Bradshaw CS, Morton AN, Hocking J, et al. (2006). High recurrence rates of bacterial vaginosis over 12 months following oral metronidazole and factors associated with recurrence. J Infect Dis 193:1478-86.

Brockert, PJ, Lachke SA, Srikantha T, et al. (2003). Phenotypic switching and mating type switching of Candida glabrata at sites of colonization. Infect Immun 71:7109-18.

Brown GD. (2006). Dectin-1: a signalling non-TLR pattern-recognition receptor. Nat Rev Immunol 6:33-43.

Brown GD, Gordon S. (2005). Immune recognition of fungal betaglucans. Cell Microbiol 7:471-9.

Buchta V, Spacek J. (2004). Microbiological findings in patients with recurrent vulvovaginal candidiasis in the Hradec Kralove Faculty Hospital 1995-2002. Ceska Gynekol 69:7-14 (in Czech).

Burchard EG, Silverman EK, Rosenwasser LJ, et al. (1999). Association between a sequence variant in the IL- 4 gene promoter and FEV 1 in asthma. Am J Respir Crit Care Med 160:919-22.

Butler G, Rasmussen MD, Lin MF, et al. (2009). Evolution of pathogenicity and sexual reproduction in eight Candida genomes. Nature 459:657-62.

Carvalho LP., Bacellar O, Neves N, et al. (2002). Downregulation of IFN $\gamma$ production in patients with recurrent vaginal candidiasis. J Allergy Clin Immunol 109:102-5.

Carvalho RJV de, Cunha CM, Silva DA, et al. (2003). IgA, IgE e subclasses de IgG anti-Candida albicans no soro e lavado vaginal de pacientes com candidíase vulvovaginal. Rev Assoc Med Bras 49: 434-8.

Cassone A, De Bernardis F, Mondello F, et al. (1987). Evidence for a correlation between proteinase secretion and vulvovaginal candidosis. J Infect Dis 156:777-83.

Cassone A, De Bernardis F, Santoni G. (2007). Anticandidal immunity and vaginitis: novel opportunities for immune intervention. Infect Immun 75:4675-86.

Cenci E, Romani L, Mencacci A, et al. (1993). Interleukin-4 and interleukin-10 inhibit nitric oxide-dependent macrophage killing of Candida albicans. Eur J Immunol 23:1034-8.

Cetin M, Ocak S, Gungoren A, Hakverdi AU. (2007). Distribution of Candida species in women with vulvovaginal symptoms and their association with different ages and contraceptive methods. Scand J Infect Dis 39:584-8.

Chaffin WL. (2008). Candida albicans cell wall proteins. Microbiol Mol Biol Rev 72:495-544.

Chaim W, Foxman B, Sobel JD. (1997). Association of recurrent vaginal candidiasis and secretory ABO and Lewis phenotype. J Infect Dis 176: 828-30.

Chakrabarti A, Nayak N, Talwar P. (1991). In vitro proteinase production by Candida species. Mycopathologia 114:163-8.

Chassot F, Negri MF, Svidzinski AE, et al. (2008). Can intrauterine contraceptive devices be a Candida albicans reservoir? Contraception 77:355-9.

Cheng G, Wozniak K, Wallig MA, et al. (2005). Comparison between Candida albicans agglutinin-like sequence gene expression patterns in human clinical specimens and models of vaginal candidiasis. Infect Immun 73:1656-63.

Cheng G, Yeater KM, Hoyer LL. (2006). Cellular and molecular biology of Candida albicans estrogen response. Eukaryot Cell 5:180-91.

Cormack BP, Ghori N, Falkow S. (1999). An adhesin of the yeast pathogen Candida glabrata mediating adherence to human epithelial cells. Science 285:578-82.

Corsello S, Spinillo A, Osnengo G, et al. (2003). An epidemiological survey of vulvovaginal candidiasis in Italy. Eur J Obstet Gynecol Reprod Biol 110:66-72.

Cotch MF, Hillier SL, Gibbs RS, Eschenbach DA. (1998). Epidemiology and outcomes associated with moderate to heavy Candida colonization during pregnancy. Vaginal infections and prematurity study group. Am J Obstet Gynecol 178:374-80.

Cremel M. (2005). Characterization of CCL20 secretion by human epithelial vaginal cells: involvement in Langerhans cell precursor attraction. J Leukoc Biol 78:158-66.

Cribby S, Taylor M, Reid G. (2008). Vaginal microbiota and the use of probiotics. Interdiscip Perspect Infect Dis 2008:1-9.

Czeizel AE, Fladung B, Vargha P. (2004). Preterm birth reduction after clotrimazole treatment during pregnancy. Eur J Obstet Gynecol Reprod Biol 116:157-63.

Czeizel AE, Rockenbauer M. (1999). A lower rate of preterm birth after clotrimazole therapy during pregnancy. Paediatr Perinat Epidemiol 13:58-64.

Dan M, Kaneti N, Levin D, et al. (2003). Vaginitis in a gynecologic practice in Israel: causes and risk factors. Isr Med Assoc J 5:629-32.

Dan M, Segal R, Marder V, Leibovitz A. (2006). Candida colonization of the vagina in elderly residents of a long-term-care hospital. Eur $\mathrm{J}$ Clin Microbiol Infect Dis 25:394-6.

Davey ME, O'toole GA. (2000). Microbial biofilms: from ecology to molecular genetics. Microbiol Mol Biol Rev 64:847-67.

De Bernardis F, Agatensi L, Ross IK, et al. (1990). Evidence for a role for secreted aspartate proteinase of Candida albicans in vulvovaginal candidiasis. J Infect Dis 161:1276-83.

De Bernardis F, Muhlschlegel FA, Cassone A, Fonzi WA. (1998). The $\mathrm{pH}$ of the host niche controls gene expression in and virulence of Candida albicans. Infect Immun 66:3317-25.

De Leon EM, Jacober SJ, Sobel JD, Foxman B. (2002). Prevalence and risk factors for vaginal Candida colonization in women with type 1 and type 2 diabetes. BMC Infect Dis 2:1.

Demirezen S, Dirlik OO, Beksaç MS. (2005). The association of Candida infection with intrauterine contraceptive device. Cent Eur J Public Health 13:32-4.

Dennerstein GJ, Ellis DH. (2001). Oestrogen, glycogen and vaginal candidiasis. Aust New Zeal J Obstet Gynaecol 41:326-8.

Dignani M, Solomkin J, Anaissie E. (2009). Candida. In: Anaissie E, McGinnis M, Pfaller M, eds. Clinical mycology. USA: Elsevier, 197-231.

Dominic RM, Shenoy S, Baliga S. (2007). Candida biofilms in medical devices: evolving trends. Kathmandu Univ Med J 5:431-6.

Donlan RM. (2002). Biofilms: microbial life on surfaces. Emerg Infect Dis 8:881-90.

Donlan RM, Costerton JW. (2002). Biofilms: survival mechanisms of clinically relevant microorganisms. Clin Microbiol Rev 15:167-93.

Douglas LJ. (2003). Candida biofilms and their role in infection. Trends Microbiol 11:30-6.

Duerr A, Heilig CM, Meikle SF, Cu-Uvin S, et al. (2003). Incident and persistent vulvovaginal candidiasis among human immunodeficiency virus-infected women: risk factors and severity. Obstet Gynecol 101: 548-56. 
Eckert L. (1998). Vulvovaginal candidiasis: clinical manifestations, risk factors, management algorithm. Obstet Gynecol 92:757-65.

Egbe CA, Onwufor UC, Omoregie R, Enabulele OI. (2011). Female reproductive tract infections among vaginal contraceptive users in Benin city, Nigeria. Genomic Med Biomarkers, Health Sci 3:49-52.

Eschenbach D. (1986). Lower genital tract infections. In: Galask RP, Larsen B, eds. Infectious diseases in the female patient. New York: Springer, 163-86.

Esim BE, Kars B, Karsidag AY, et al. (2010). Diagnosis of vulvovaginitis: comparison of clinical and microbiological diagnosis. Arch Gynecol Obstet 282:515-19.

Essner R, Rhoades K, McBride WH, et al. (1989). IL-4 down-regulates IL-1 and TNF gene expression in human monocytes. J Immunol 142: 3857-61.

Fan SR, Liao QP, Liu XP, et al. (2008a). Vaginal allergic response in women with vulvovaginal candidiasis. Int J Gynaecol Obstet 101: $27-30$.

Fan SR, Liu XP, Li JW. (2008b). Clinical characteristics of vulvovaginal candidiasis and antifungal susceptibilities of Candida species isolates among patients in southern China from 2003 to 2006. J Obstet Gynaecol Res 34:561-66.

Faraji R, Rahimi M, Assarehzadegan M. (2012). Prevalence of vaginal candidiasis infection in women referred to Kermanshah hygienic centers, Iran in 2010. Life Sci J 9:1280-3.

Ferrer J. (2000). Vaginal candidosis: epidemiological and etiological factors. Int J Gynaecol Obstet 71:21-7.

Ferris HA, Kahn CR. (2012). New mechanisms of glucocorticoidinduced insulin resistance: make no bones about it. J Clin Invest 122: 3854-7.

Ferwerda B. (2009). A family with human dectin-1 deficiency and mucocutanous fungal infections. Interscience conference on antimicrobial agents and chemotherapy; San Francisco, USA..

Fidel PL. (2005). Immunity in vaginal candidiasis. Curr Opin Infect Dis 18:107-11.

Fidel PL, Cutright J, Steele C. (2000). Effects of reproductive hormones on experimental vaginal candidiasis. Infect Immun 68:651-57.

Fidel PL, Ginsburg KA, Cutright JL, et al. (1997). Vaginal-associated immunity in women with recurrent vulvovaginal candidiasis: evidence for vaginal Th1-type responses following intravaginal challenge with Candida antigen. J Infect Dis 176:728-39.

Fidel PL, Luo W, Steele C, et al. (1999a). Analysis of vaginal cell populations during experimental vaginal candidiasis. Infect Immun 67:3135-40.

Fidel PL, Lynch M., Sobel J. (1995). Circulating CD4 and CD8 T cells have little impact on host defense against experimental vaginal candidiasis. Infect. Immun 63:2403-8.

Fidel PL, Sobel JD. (1996). Immunopathogenesis of recurrent vulvovaginal candidiasis. Clin Microbiol Rev 9:335-48.

Fidel PL, Vazquez JA, Sobel JD. (1999b). Candida glabrata: review of epidemiology, pathogenesis, and clinical disease with comparison to C. albicans. Clin Microbiol Rev 12:80-96.

Fidel PL, Wolf NA, KuKuruga MA. (1996). T lymphocytes in the murine vaginal mucosa are phenotypically distinct from those in the periphery. Infect Immun 64:3793-9.

Fleetwood L, Landgren BM, Eneroth P. (1984). Changes in soluble proteins in cervical mucus during midcycle in normally menstruating women. Gynecol Obstet Invest 18:27-33.

Foxman B. (1990). The epidemiology of vulvovaginal candidiasis: risk factors. Am J Public Health 80:329-31.

Foxman B, Barlow R, D’Arcy H, et al. (2000). Candida vaginitis: selfreported incidence and associated costs. Sex Transm Dis 27:230-5.

Fukushima C, Matsuse H, Tomari S, et al. (2003). Oral candidiasis associated with inhaled corticosteroid use: comparison of fluticasone and beclomethasone. Ann Allergy Asthma Immunol 90:646-51.

Fulurija A, Ashman RB, Papadimitriou JM. (1996). Neutrophil depletion increases susceptibility to systemic and vaginal candidiasis in mice, and reveals differences between brain and kidney in mechanisms of host resistance. Microbiology 142:3487-96.

Ganz T. (2003). Defensins: antimicrobial peptides of innate immunity. Nat Rev Immunol 3:710-20.

Geiger AM, Foxman B. (1996). Risk factors for vulvovaginal candidiasis: a case-control study among university students. Epidemiology 7: $182-7$.

Ghannoum MA. (2000). Potential role of phospholipases in virulence and fungal pathogenesis. Clin Microbiol Rev 13:122-43.
Gibbs RS. (1987). Microbiology of the female genital tract. Am J Obstet Gynecol 156:491-5.

Gilmore BJ, Retsinas EM, Lorenz JS, Hostetter MK. (1988). An iC3b receptor on Candida albicans: structure, function, and correlates for pathogenicity. J Infect Dis 157:38-46.

Giraldo PC, Babula O, Gonçalves AK, et al. (2007). Mannose-binding lectin gene polymorphism, vulvovaginal candidiasis, and bacterial vaginosis. Obstet Gynecol 109:1123-8.

Giraldo, PC, do Amaral RL, Gonçalves AK, et al. (2005). Influência da frequiência de coitos vaginais e da prática de duchas higiênicas sobre o equilíbrio da microbiota vaginal. Rev Bras Ginecol e Obs 27: 257-62.

Goswami D, Goswami R, Banerjee U, et al. (2006). Pattern of Candida species isolated from patients with diabetes mellitus and vulvovaginal candidiasis and their response to single dose oral fluconazole therapy. J Infect 52:111-17.

Goswami R, Dadhwal V, Tejaswi S, et al. (2000). Species-specific prevalence of vaginal candidiasis among patients with diabetes mellitus and its relation to their glycaemic status. J Infect 41:162-6.

Gough PM, Warnock DW, Richardson MD, et al. (1984). IgA and IgG antibodies to Candida albicans in the genital tract secretions of women with or without vaginal candidosis. Sabouraudia 22:265-71.

Gow NAR, Netea MG, Munro CA, et al. (2007). Immune recognition of Candida albicans beta-glucan by dectin-1. J Infect Dis 196:1565-71.

Grigoriou O, Baka S, Makrakis E, et al. (2006). Prevalence of clinical vaginal candidiasis in a university hospital and possible risk factors. Eur J Obstet Gynecol Reprod Biol 126:121-5.

Gunther LSA, Martins HP, Gimenes F, et al. (2014). Prevalence of Candida albicans and non-albicans isolates from vaginal secretions: comparative evaluation of colonization, vaginal candidiasis and recurrent vaginal candidiasis in diabetic and non-diabetic women. São Paulo Med J 132:116-20.

Guyton A, Hall J. (2006). Fisiologia feminina antes da gravidez e hormônios femininos. In: Guyton A, Hall J, eds. Tratado de Fisiologia Médica. Rio de Janeiro: Elsevier, 1011-26.

Guzel AB, Ilkit M, Akar T, et al. (2011). Evaluation of risk factors in patients with vulvovaginal candidiasis and the value of chromID Candida agar versus CHROMagar Candida for recovery and presumptive identification of vaginal yeast species. Med Mycol 49: $16-25$.

Harriott MM, Lilly EA, Rodriguez TE, et al. (2010). Candida albicans forms biofilms on the vaginal mucosa. Microbiology 156:3635-44.

Hazen KC. (1989). Participation of yeast cell surface hydrophobicity in adherence of Candida albicans to human epithelial cells. Infect Immun 57:1894-900.

Hellberg D, Zdolsek B, Nilsson S, Mårdh PA. (1995). Sexual behavior of women with repeated episodes of vulvovaginal candidiasis. Eur J Epidemiol 11:575-9.

Hillier SL, Krohn MA, Klebanoff SJ, Eschenbach DA. (1992). The relationship of hydrogen peroxide-producing lactobacilli to bacterial vaginosis and genital microflora in pregnant women. Obstet Gynecol 79:369-73.

Hilton E, Chandrasekaran V, Rindos P, Isenberg HD. (1995). Association of recurrent candidal vaginitis with inheritance of Lewis blood group antigens. J Infect Dis 172:1616-19.

Hodoglugil NN, Aslan D, Bertan M. (2000). Intrauterine device use and some issues related to sexually transmitted disease screening and occurrence. Contraception 61:359-64.

Holanda AAR de, Fernandes AC, Bezerra CM, et al. (2007). Candidíase vulvovaginal: sintomatologia, fatores de risco e colonização anal concomitante. Rev Bras Ginecol Obs 29:3-9.

Holland J, Young ML, Lee O, Chen SCA. (2003). Vulvovaginal carriage of yeasts other than Candida albicans. Sex Transm Infect 79:249-50.

Hooton TM, Roberts PL, Stamm WE. (1994). Effects of recent sexual activity and use of a diaphragm on the vaginal microflora. Clin Infect Dis 19:274-8.

Hostetter MK. (1990). Handicaps to host defense. Effects of hyperglycemia on C3 and Candida albicans. Diabetes 39:271-5.

Hostetter MK. (1994). Adhesins and ligands involved in the interaction of Candida spp. with epithelial and endothelial surfaces. Clin Microbiol Rev 7:29-42.

Hostetter MK, Lorenz JS, Preus L, Kendrick KE. (1990). The iC3b receptor on Candida albicans: subcellular localization and modulation of receptor expression by glucose. J Infect Dis 161:761-8. 
Hoyer LL, Fundyga R, Hecht JE, et al. (2001). Characterization of agglutinin-like sequence genes from non-albicans Candida and phylogenetic analysis of the ALS family. Genetics 157:1555-67.

Hoyer LL, Green CB, Oh SH, Zhao X. (2008). Discovering the secrets of the Candida albicans agglutinin-like sequence (ALS) gene family-a sticky pursuit. Med Mycol 46:1-15.

Hube B, Sanglard D, Odds FC, et al. (1997). Disruption of each of the secreted aspartyl proteinase genes $S A P 1, S A P 2$, and $S A P 3$ of Candida albicans attenuates virulence. Infect Immun 65:3529-38.

Ip WK, Lau YL. (2004). Role of mannose-binding lectin in the innate defense against Candida albicans: enhancement of complement activation, but lack of opsonic function, in phagocytosis by human dendritic cells. J Infect Dis 190:632-40.

Jabeen R, Siddiqi I. (2014). Frequency of vaginal candidiasis amongst pregnant women and effect of predisposing factors. Int Ophthalmol Updat $12: 140-3$.

Jackson ST, Mullings AM, Rainford L, Miller A. (2005). The epidemiology of mycotic vulvovaginitis and the use of antifungal agents in suspected mycotic vulvovaginitis and its implications for clinical practice. West Indian Med J 54:192-5.

Jain N, Kohli R, Cook E, et al. (2007). Biofilm formation by and antifungal susceptibility of Candida isolates from urine. Appl Environ Microbiol 73:1697-703.

Jayatilake JA, Samaranayake YH, Cheung LK, Samaranayake LP. (2006). Quantitive evaluation of tissue invasion by wild type, hyphal and SAP mutants i recosntiyued human oral epithelium. J Oral Pathol Med 35:481-91.

Jouault T, Behi MEA-E, Martinez-Esparza M, et al. (2006). Specific recognition of Candida albicans by macrophages requires galectin-3 to discriminate Saccharomyces cerevisiae and needs association with TLR2 for signaling. J Immunol 177:4679-87.

Kalo A, Segal E. (1988). Interaction of Candida albicans with genital mucosa: effect of sex hormones on adherence of yeasts in vitro. Can J Microbiol 34:224-28.

Kalo-Klein A, Witkin SS. (1989). Candida albicans: cellular immune system interactions during different stages of the menstrual cycle. Am J Obstet Gynecol 161:1132-36.

Kalo-Klein A, Witkin SS. (1990). Prostaglandin E2 enhances and gamma interferon inhibits germ tube formation in Candida albicans. Infect Immun 58:260-2.

Kalo-Klein A, Witkin SS. (1991). Regulation of the immune response to Candida albicans monocytes and progesterone. Am J Obstet Gynecol 164:1351-54.

Kamath P, Pais M, Nayak MG. (2013). Risk of vaginal candidiasis among pregnant women. Int J Curr Microbiol Appl Sci 2:141-46.

Keller MJ, Guzman E, Hazrati E, et al. (2007). PRO 2000 elicits a decline in genital tract immune mediators without compromising intrinsic antimicrobial activity. AIDS 21:467-76.

King AE, Critchley HO, Kelly RW. (2000). Presence of secretory leukocyte protease inhibitor in human endometrium and first trimester decidua suggests an antibacterial protective role. Mol Hum Reprod 6: 191-6.

King AE, Fleming DC, Critchley HO, Kelly RM. (2003). Differential expression of the natural antimicrobials, beta-defensins 3 and 4, in human endometrium. J Reprod Immunol 59:1-16.

King RD, Lee JC, Morris AL. (1980). Adherence of Candida albicans and other Candida species to mucosal epithelial cells. Infect Immun 27:667-74.

Kumamoto CA, Vinces MD. (2005). Contributions of hyphae and hyphaco-regulated genes to Candida albicans virulence. Cell Microbiol 7: 1546-54.

Lal P, Agarwal V, Pruthi P, et al. (2008). Biofilm formation by Candida albicans isolated from intrauterine devices. Indian J Microbiol 48: 438-44.

Lee NC, Rubin GL, Ory HW, Burkman RT. (1983). Type of intrauterine device and the risk of pelvic inflammatory disease. Obstet Gynecol $62: 1-6$

Lev-Sagie A, Prus D, Linhares IM, et al. (2009). Polymorphism in a gene coding for the inflammasome component NALP3 and recurrent vulvovaginal candidiasis in women with vulvar vestibulitis syndrome. Am J Obstet Gynecol 200:303.e1-6.

Lian CH, Liu WD. (2007). Differential expression of Candida albicans secreted aspartyl proteinase in human vulvovaginal candidiasis. Mycoses 50:383-90.
Linhares IM., Witkin SS, Miranda SD, et al. (2001). Differentiation between women with vulvovaginal symptoms who are positive or negative for Candida species by culture. Infect Dis Obstet Gynecol 9: $221-5$.

Lipscombe RJ, Sumiya M, Summerfield JA, Turner MW. (1995). Distinct physicochemical characteristics of human mannose binding protein expressed by individuals of differing genotype. Immunology 85:660-7.

Liu F, Liao Q, Liu Z. (2006). Mannose-binding lectin and vulvovaginal candidiasis. Int J Gynaecol Obstet 92:43-7.

Liu YJ. (2001). Dendritic cell subsets and lineages, and their functions in innate and adaptive immunity. Cell 106:259-62.

Loose DS, Stevens D, Schurman DJ, Feldman D. (1983). Distribution of a corticosteroid-binding protein in Candida and other fungal genera. J Gen Microbiol 129:2379-85.

Luo G, Samaranayake LP, Cheung BP, Tang G. (2004). Reverse transcriptase polymerase chain reaction (RT-PCR) detection of HLP gene expression in Candida glabrata and its possible role in in vitro haemolysin production. APMIS 112:283-90.

Lynch ME, Sobel JD. (1994). Comparative in vitro activity of antimycotic agents against pathogenic vaginal yeast isolates. J.Med Vet Mycol 32:267-74.

Madani ND, Malloy PJ, Rodriguez-Pombo P, et al. (1994). Candida albicans estrogen-binding protein gene encodes an oxidoreductase that is inhibited by estradiol. Proc Natl Acad Sci USA 91:922-6.

Mahmoudi RM, Zafarghandi S, Abbasabadi B, Tavallaee M. (2011). The epidemiology of Candida species associated with vulvovaginal candidiasis in an Iranian patient population. Eur J Obstet Gynecol Reprod Biol 155:199-203.

Markos AR, Wade AA, Walzman M. (1992). Oral sex and recurrent vulvo-vaginal candidiasis. Genitourin Med 68:61-2.

McGroarty JA, Soboh F, Bruce AW, Reid G. (1990). The spermicidal compound nonoxynol-9 increases adhesion of Candida species to human epithelial cells in vitro. Infect Immun 58:2005-7.

McNagny SE. (1999). Prescribing hormone replacement therapy for menopausal symptoms. Ann Intern Med 131:605-16.

Medzhitov R. (2001). Toll-like receptors and innate immunity. Nat Rev Immunol 1:135-45.

Merkerová M, Dostál J, Hradilek M, et al. (2006). Cloning and characterization of Sapp2p, the second aspartic proteinase isoenzyme from Candida parapsilosis. FEMS Yeast Res 6:1018-26.

Miller L, Patton DL, Meier A, et al. (2000). Depomedroxyprogesteroneinduced hypoestrogenism and changes in vaginal flora and epithelium. Obstet Gynecol 96:431-9.

Mitchell H. (2004). Vaginal discharge-causes, diagnosis, and treatment. BMJ 328:1306-8.

Mohandas V, Ballal M. (2011). Distribution of Candida species in different clinical samples and their virulence: biofilm formation, proteinase and phospholipase production: a study on hospitalized patients in southern India. J Glob Infect Dis 3:4-8.

Mohanty S, Xess I, Hasan F, et al. (2007). Prevalence and susceptibility to fluconazole of Candida species causing vulvovaginitis. Indian J Med Res 126:216-19.

Moragues MD, Omaetxebarria MJ, Elguezabal N, et al. (2003). A monoclonal antibody directed against a Candida albicans cell wall mannoprotein exerts three anti-C. albicans activities. Infect Immun 71:5273-9.

Morrow B, Srikantha T, Soll DR. (1992). Transcription of the gene for a pepsinogen, PEP1, is regulated by white-opaque switching in Candida albicans. Mol Cell Biol 12:2997-3005.

Mostad SB, Overbaugh J, DeVange DM, et al. (1997). Hormonal contraception, vitamin A deficiency, and other risk factors for shedding of HIV-1 infected cells from the cervix and vagina. Lancet 350:922-7.

Muhlschlegel F, Fonzi W. (1997). PHR2 of Candida albicans encodes a functional homolog of the $\mathrm{pH}$-regulated gene PHRI with an inverted pattern of pH-dependent expression. Mol Cell Biol 17:5960-7.

Naglik JR, Rodgers CA, Shirlaw PJ, et al. (2003). Differential expression of Candida albicans secreted aspartyl proteinase and phospholipase B Genes in humans correlates with active oral and vaginal infections. J Infect Dis 188:469-79.

Neerja J, Aruna A, Paramjeet G. (2006). Significance of Candida culture in women with vulvovaginal symptoms. Obstet Gynecol 56:139-41.

Nelson M, Wanjiru W, Margaret MW. (2013). Prevalence of vaginal candidiasis and determination of the occurrence of Candida species in 
pregnant women attending the antenatal clinic of Thika District Hospital, Kenya. Open J Med Microbiol 3:264-72.

Ness RB, Hillier SL, Richter HE, et al. (2003). Why women douche and why they may or may not stop. Sex Transm Dis 30:71-4.

Netea MG, Brown GD, Kullberg BJ, Gow NA. (2008). An integrated model of the recognition of Candida albicans by the innate immune system. Nat Rev Microbiol 6:67-78.

Neth O, Jack DL, Dodds AW, et al. (2000). Mannose-binding lectin binds to a range of clinically relevant microorganisms and promotes complement deposition. Infect Immun 68:688-93.

Neves NA, Carvalho LP, De Oliveira MA, et al. (2005). Association between atopy and recurrent vaginal candidiasis. Clin Exp Immunol 142:167-71.

Niruthisard S, Roddy RE, Chutivongse S. (1991). The effects of frequent nonoxynol-9 use on the vaginal and cervical mucosa. Sex Transm Dis 18:176-9.

Nobile CJ, Andes DR, Nett JE, et al. (2006). Critical role of Bcr1dependent adhesins in C. albicans biofilm formation in vitro and in vivo. PLoS Pathog 2:63.

Nohmi T, Abe S, Dobashi K, et al. (1995). Suppression of anti-Candida activity of murine neutrophils by progesterone in vitro: a possible mechanism in pregnant women's vulnerability to vaginal candidiasis. Microbiol Immunol 39:405-9.

North BB. (1988). Vaginal contraceptives. Effective protection from sexually transmitted diseases for women? J Reprod Med 33:307-11.

Nwadioha SI, Egah DZ, Alao OO, Iheanacho E. (2010). Risk factors for vaginal candidiasis among women attending primary health care centers of Jos, Nigeria. J Clin Med Res 2:110-13.

Nyirjesy P, Weitz M, Grody M, Lorber B. (1997). Over-the-counter and alternative medicines in the treatment of chronic vaginal symptoms. Obstet Gynecol 90:50-3.

Odds FC. (2008). Secreted proteinases and Candida albicans virulence. Microbiology 154:3245-6.

Okkers DJ, Dicks LM, Silvester M, et al. (1999). Characterization of pentocin TV35b, a bacteriocin-like peptide isolated from Lactobacillus pentosus with a fungistatic effect on Candida albicans. J Appl Microbiol 87:726-34.

Okungbowa FI, Isikhuemhen OS, Dede AP. (2003). The distribution frequency of Candida species in the genitourinary tract among symptomatic individuals in Nigerian cities. Rev Iberoam Micol 20: 60-3.

Otero L, Palacio V, Carreño F, et al. (1998). Vulvovaginal candidiasis in female sex workers. Int J STD AIDS 9:526-30.

Oviasogie F, Okungbowa F. (2009). Candida species amongst pregnant women in Benin city, Nigeria: effect of predisposing factors. African J Clin Exp Microbiol 10:92-8.

Ozcan SK, Budak F, Yucesoy G, et al. (2006). Prevalence, susceptibility profile and proteinase production of yeasts causing vulvovaginitis in Turkish women. APMIS 114:139-45.

Pál Z, Urbán E, Dósa E, et al. (2005). Biofilm formation on intrauterine devices in relation to duration of use. J Med Microbiol 54:1199-203.

Pappas PG, Kauffman CA, Andes D, et al. (2009). Clinical practice guidelines for the management of candidiasis: 2009 update by the Infectious Diseases Society of America. Clin Infect Dis 48:503-35.

Parewijck W, Claeys G, Thiery M, Kets H. (1988). Candidiasis in women fitted with an intrauterine contraceptive device. Br J Obstet Gynaecol 95:408-10.

Parr M, Parr E. (1994). Mucosal immunity in the female and male reproductive tracts. In: Ogra P, Lamm M, McGhee J, et al., eds. Handbook of Mucosal Immunology. California: Academic Press, 677-89.

Parveen N, Munir AA, Din I, Majeed R. (2008). Frequency of vaginal candidiasis in pregnant women attending routine antenatal clinic. J Coll Physicians Surg Pak 18:154-7.

Patel DA, Gillespie B, Sobel JD, et al. (2004). Risk factors for recurrent vulvovaginal candidiasis in women receiving maintenance antifungal therapy: results of a prospective cohort study. Am J Obstet Gynecol 190:644-53.

Paulitsch A, Weger W, Ginter-Hanselmayer G, et al. (2006). A 5-year (2000-2004) epidemiological survey of Candida and non-Candida yeast species causing vulvovaginal candidiasis in Graz, Austria. Mycoses 49:471-5.

Peer AK, Hoosen AA, Seedat MA, et al. (1993). Vaginal yeast infections in diabetic women. S Afr Med J 83:727-9.
Pellis V, De Seta F, Crovella S, et al. (2005). Mannose binding lectin and $\mathrm{C} 3$ act as recognition molecules for infectious agents in the vagina. Clin Exp Immunol 139:120-6.

Pereira ID, de Souza AE, Feio RS, et al. (1996). Vulvovaginites por Candida albicans em pacientes ambulatoriais do Hospital Universitário Betina Ferro de Souza. Rev Bras Anal Clin 28:53-4.

Petersen KA, Matthiesen F, Agger T, et al. (2006). Phase I safety, tolerability, and pharmacokinetic study of recombinant human mannan-binding lectin. J Clin Immunol 26:465-75.

Pichová I, Pavlícková L, Dostál J, et al. (2001). Secreted aspartic proteases of Candida albicans, Candida tropicalis, Candida parapsilosis and Candida lusitaniae. Inhibition with peptidomimetic inhibitors. Eur J Biochem 268:2669-77.

Pietrella D, Rachini A, Pines M, et al. (2011). Th17 cells and IL-17 in protective immunity to vaginal candidiasis. PLoS One 6:e22770.

Pirotta MV, Garland SM. (2006). Genital Candida species detected in samples from women in Melbourne, Australia, before and after treatment with antibiotics. J Clin Microbiol 44:3213-17.

Plantinga TS, van der Velden WJ, Ferwerda B, et al. (2009). Early stop polymorphism in human DECTIN-1 is associated with increased Candida colonization in hematopoietic stem cell transplant recipients. Clin Infect Dis 49:724-32.

Powell BL, Frey CL, Drutz DJ. (1984). Identification of a $17 \beta$-estradiol binding protein in Candida albicans and Candida (Torulopsis) glabrata. Exp Mycol 8:304-13.

Pruthi V, Al-Janabi A, Pereira BM. (2003). Characterization of biofilm formed on intrauterine devices. Indian J Med Microbiol 21:161-5.

Psaty BM. (1993). A review of the association of estrogens and progestins with cardiovascular disease in postmenopausal women. Arch Intern Med 153:1421-7.

Pudney J, Quayle AJ, Anderson DJ. (2005). Immunological microenvironments in the human vagina and cervix: mediators of cellular immunity are concentrated in the cervical transformation zone. Biol Reprod 73:1253-63.

Quayle AJ, Porter EM, Nussbaum AA, et al. (1998). Gene expression, immunolocalization, and secretion of human defensin-5 in human female reproductive tract. Am J Pathol 152:1247-58.

Ramage G, Mowat E, Jones B, et al. (2009). Our current understanding of fungal biofilms. Crit Rev Microbiol 35:340-55.

Ramage G, Rajendran R, Sherry L, Williams C. (2012). Fungal biofilm resistance. Int J Microbiol 2012:528521.

Ramage G, VandeWalle K, López-Ribot JL, Wickes BL. (2002). The filamentation pathway controlled by the Efg1 regulator protein is required for normal biofilm formation and development in Candida albicans. FEMS Microbiol Lett 214:95-100.

Ray D, Goswami R, Banerjee U, et al. (2007). Prevalence of Candida glabrata and its response to boric acid vaginal suppositories in comparison with oral fluconazole in patients with diabetes and vulvovaginal candidiasis. Diabetes care 30:312-17.

Redding SW, Kirkpatrick WR, Saville S, et al. (2003). Multiple patterns of resistance to fluconazole in Candida glabrata isolates from a patient with oropharyngeal candidiasis receiving head and neck radiation. J Clin Microbiol 41:619-22.

Reed BD. (1992). Risk factors for Candida vulvovaginitis. Obstet Gynecol Surv 47:551-60.

Reed BD, Gorenflo DW, Gillespie BW, et al. (2000). Sexual behaviors and other risk factors for Candida vulvovaginitis. J Womens Health Gend Based Med 9:645-55.

Reed BD, Zazove P, Pierson CL, et al. (2003). Candida transmission and sexual behaviors as risks for a repeat episode of Candida vulvovaginitis. J Women's Heal 12:979-89.

Regúlez P, Fernández JF, Moragues MD, et al. (1994). Detection of antiCandida albicans $\mathrm{IgE}$ antibodies in vaginal washes from patients with acute vulvovaginal candidiasis. Gynecol Obstet Invest 37:110-14.

Ribeiro MA, Dietze R, Paula CR, et al. (2001). Susceptibility profile of vaginal yeast isolates from Brazil. Mycopathologia 151:5-10.

Richardson M, Rautemaa R. (2009). How the host fights against Candida infections. Front Biosci 14:4363-75.

Richter SS, Galask RP, Messer SA, et al. (2005). Antifungal susceptibilities of Candida species causing vulvovaginitis and epidemiology of recurrent cases. J Clin Microbiol 43:2155-62.

Rivers CA, Adaramola OO, Schwebke JR. (2011). Prevalence of bacterial vaginosis and vulvovaginal candidiasis mixed infection in a southeastern american STD clinic. Sex Transm Dis 38:672-4. 
Roddy RE, Cordero M, Cordero C, Fortney JA. (1993). A dosing study of nonoxynol-9 and genital irritation. Int J STD AIDS 4:165-70.

Rosa MI da, Rumel D. (2004). Fatores associados à candidíase vulvovaginal: estudo exploratório. Rev Bras Ginecol Obs 26:65-70.

Rosentul D, Delsing C, Joosten LA, et al. (2009). Polymorphism in innate immunity genes and susceptibility to recurrent vulvovaginal candidiasis. J Med Mycol 19:191-6.

Rosenwasser LJ, Klemm DJ, Dresback JK, et al. (1995). Promoter polymorphisms in the chromosome 5 gene cluster in asthma and atopy. Clin Exp Allergy 25:74-8.

Røttingen JA, Cameron DW, Garnett GP. (2001). A systematic review of the epidemiologic interactions between classic sexually transmitted diseases and HIV: how much really is known? Sex Transm Dis 28: 579-97.

Russell MW, Mestecky J. (2002). Humoral immune responses to microbial infections in the genital tract. Microbes Infect 4:667-77.

Rylander E, Berglund AL, Krassny C, Petrini B. (2004). Vulvovaginal Candida in a young sexually active population: prevalence and association with oro-genital sex and frequent pain at intercourse. Sex Transm Infect 80:54-7.

Safdar A, Armstrong D, Cross EW, Perlin DS. (2002). Prospective epidemiologic analysis of triazole-resistant nosocomial Candida glabrata isolated from patients at a comprehensive cancer center. Int J Infect Dis 6:198-201.

Samaranayake YH, Dassanayake RS, Cheung BP, et al. (2006). Differential phospholipase gene expression gene expression by Candida albicans in artifical media and cultured human oral epithelium. APMIS 114:857-66.

Saporiti AM, Gómez D, Levalle S, et al. (2001). Vaginal candidiasis: etiology and sensitivity profile to antifungal agents in clinical use. Rev Argent Microbiol 33:217-22.

Savage DC. (1969). Microbial interference between indigenous yeast and lactobacilli in the rodent stomach. J Bacteriol 98:1278-83.

Schaller M, Bein M, Korting HC, et al. (2003). The secreted aspartyl proteinases Sap1 and Sap2 cause tissue damage in an in vitro model of vaginal candidiasis based on reconstituted human vaginal epithelium. Infect Immun 71:3227-34.

Schaller M, Borelli C, Korting HC, Hube B. (2005). Hydrolytic enzymes as virulence factors of Candida albicans. Mycoses 48:365-77.

Schmid J, Rotman M, Reed B, et al. (1993). Genetic similarity of Candida albicans strains from vaginitis patients and their partners. J Clin Microbiol 31:39-46.

Schreiber CA, Meyn LA, Creinin MD, et al. (2006). Effects of long-term use of nonoxynol-9 on vaginal flora. Obstet Gynecol 107:136-43.

Schuman P, Capps L, Peng G, et al. (1997). Weekly fluconazole for the prevention of mucosal candidiasis in women with HIV infection. A randomized, double-blind, placebo-controlled trial. Terry Beirn Community Programs for Clinical Research on AIDS. Ann Intern Med 126:689-96.

Schuman P, Sobel JD, Ohmit SE, et al. (1998). Mucosal candidal colonization and candidiasis in women with or at risk for human immunodeficiency virus infection. HIV Epidemiology Research Study (HERS) Group. Clin Infect Dis 27:1161-7.

Scott TG, Curran B, Smyth CJ. (1989). Electron microscopy of adhesive interactions between Gardnerella vaginalis and vaginal epithelial cells, McCoy cells and human red blood cells. J Gen Microbiol 135: 475-80.

Segal E, Soroka A, Schechter A. (1984). Correlative relationship between adherence of Candida albicans to human vaginal epithelial cells in vitro and candidal vaginitis. Sabouraudia 22:191-200.

Shu'aibu I, Tennu PD, Fatima UM, et al. (2014). Incidence of vulvovaginal candidiasis associated with Candida albicans among pregnant women attending Gombe State Specialist Hospital, Gombe, Nigeria. Bayero J Pure Appl Sci 6:84-8.

Sidrim J, Rocha M. (2004). Micologia Médica à luz de autores contemporâneos. Rio de Janeiro: Guanabara Koogan.

Silva, CR, de Melo KE, Leão MV, et al. (2008). Presença de Candida nas mucosas vaginal e bucal e sua relação com IgA salivar. Rev Bras Ginecol e Obs 30:300-5.

Silva S, Henriques M, Martins A, et al. (2009). Biofilms of non-Candida albicans Candida species: quantification, structure and matrix composition. Med Mycol 47:681-9.

Silva S, Negri M, Henriques M, et al. (2012). Candida glabrata, Candida parapsilosis and Candida tropicalis: biology, epidemiology, pathogenicity and antifungal resistance. FEMS Microbiol Rev 36:288-305.
Skowronski R, Feldman D. (1989). Characterization of an estrogenbinding protein in the yeast Candida albicans. Endocrinology 124: 1965-72.

Sobel JD. (2005). Genital candidiasis. Medicine 33:62-5.

Sobel JD. (2007). Vulvovaginal candidosis. Lancet 369:1961-71.

Sobel JD. (2014). Genital candidiasis. Medicine 38:186-90.

Sobel JD, Brooker D, Stein GE, et al. (1995). Single oral dose fluconazole compared with conventional clotrimazole topical therapy of Candida vaginitis. Fluconazole vaginitis study group. Am J Obstet Gynecol 172:1263-8.

Sobel JD, Chaim W, Nagappan V, Leaman D. (2003). Treatment of vaginitis caused by Candida glabrata: use of topical boric acid and flucytosine. Am J Obstet Gynecol 189:1297-300.

Sobel JD, Faro S, Force RW, et al. (1998). Vulvovaginal candidiasis: epidemiologic, diagnostic, and therapeutic considerations. Am J Obstet Gynecol 178:203-11.

Sobel JD, Kapernick PS, Zervos M, et al. (2001). Treatment of complicated Candida vaginitis: comparison of single and sequential doses of fluconazole. Am J Obstet Gynecol 185:363-69.

Sobel JD, Leamna D. (1998). Suppressive maintenance therapy of recurrent bacterial vaginosis utilizing $0.75 \%$ metronidazole vaginal gel. In: Abstracts of the second international meeting on bacterial vaginosis. Aspen.

Sobel JD, Myers PG, Kaye D, Levison ME. (1981). Adherence of Candida albicans to human vaginal and buccal epithelial cells. J Infect Dis 143:76-82.

Sobel JD, Wiesenfeld HC, Martens M, et al. (2004). Maintenance fluconazole therapy for recurrent vulvovaginal candidiasis. N Engl J Med 351:876-83.

Sojakova M, Liptajova D, Borovsky M, Subik J. (2004). Fluconazole and itraconazole susceptibility of vaginal yeast isolates from Slovakia. Mycopathologia 157:163-9.

Soll DR. (1988). High-frequency switching in Candida albicans and its relations to vaginal candidiasis. Am J Obstet Gynecol 158:997-1001.

Soll DR. (1997). Gene regulation during high-frequency switching in Candida albicans. Microbiology 143:279-88.

Soll DR, Galask R, Isley S, et al. (1989). Switching of Candida albicans during successive episodes of recurrent vaginitis. J Clin Microbiol 27: 681-90.

Soll DR, Langtimm CJ, McDowell J, et al. (1987). High-frequency switching in Candida strains isolated from vaginitis patients. J Clin Microbiol 25:1611-22.

Spacek J, Buchta V, Jílek P, Förstl M. (2007). Clinical aspects and luteal phase assessment in patients with recurrent vulvovaginal candidiasis. Eur J Obstet Gynecol Reprod Biol 131:198-202.

Spellberg BJ, Ibrahim AS, Avanesian V, et al. (2006). Efficacy of the anti-Candida rAls3p-N or rAls1p-N vaccines against disseminated and mucosal candidiasis. J Infect Dis 194:256-60.

Spinillo A, Bernuzzi AM, Cevini C, et al. (1997a). The relationship of bacterial vaginosis, Candida and trichomonas infection to symptomatic vaginitis in postmenopausal women attending a vaginitis clinic. Maturitas 27:253-60.

Spinillo A, Capuzzo E, Acciano S, et al. (1999). Effect of antibiotic use on the prevalence of symptomatic vulvovaginal candidiasis. Am J Obstet Gynecol 180:14-17.

Spinillo A, Capuzzo E, Gulminetti R, et al. (1997b). Prevalence of and risk factors for fungal vaginitis caused by non-albicans species. Am J Obstet Gynecol 176:138-41.

Spinillo A, Capuzzo E, Nicola S, et al. (1995). The impact of oral contraception on vulvovaginal candidiasis. Contraception 51:293-7.

Spinillo A, Nicola S, Colonna L, et al. (1994). Frequency and significance of drug resistance in vulvovaginal candidiasis. Gynecol Obstet Invest 38:130-3.

Spinillo A, Pizzoli G, Colonna L, et al. (1993). Epidemiologic characteristics of women with idiopathic recurrent vulvovaginal candidiasis. Obstet Gynecol 81:721-7.

Stehr F, Felk A, Gácser A, et al. (2004). Expression analysis of the Candida albicans lipase gene family during experimental infections and in patient samples. FEMS Yeast Res 4:401-8.

Sumiya M, Tabona P, Arai T, et al. (1991). Molecular basis of opsonic defect in immunodeficient children. Lancet 337:1569-70.

Swidsinski A, Mendling W, Loening-Baucke V, et al. (2008). An adherent Gardnerella vaginalis biofilm persists on the vaginal epithelium after standard therapy with oral metronidazole. Am J Obstet Gynecol 198:97.e1-6. 
Tamura NK, Negri MF, Bonassoli LA, Svidzinski TI. (2007). Fatores de virulência de Candida spp isoladas de cateteres venosos e mãos de servidores hospitalares. Rev Soc Bras Med Trop 40:91-3.

Tarry W, Fisher M, Shen S, Mawhinney M. (2005). Candida albicans: the estrogen target for vaginal colonization. J Surg Res 129:278-82.

Taylor BN, Staib P, Binder A. (2005). Profile of Candida albicanssecreted aspartic proteinase elicited during vaginal infection. Infect Immun 73:1828-35.

Thein ZM, Seneviratne CJ, Samaranayake YH, Samaranayake LP. (2009). Community lifestyle of Candida in mixed biofilms: a mini review. Mycoses 52:467-75.

Tibaldi C, Cappello N, Latino MA, et al. (2009). Vaginal and endocervical microorganisms in symptomatic and asymptomatic non-pregnant females: risk factors and rates of occurrence. Clin Microbiol Infect 15:670-9.

Togni G, Sanglard D, Falchetto R, Monod M. (1991). Isolation and nucleotide sequence of the extracellular acid protease gene (ACP) from the yeast Candida tropicalis. FEBS Lett 286:181-5.

Tooley PJ. (1985). Patient and doctor preferences in the treatment of vaginal candidosis. Practitioner 229:655-60.

Vargas K, Messer SA, Pfaller M, et al. (2000). Elevated phenotypic switching and drug resistance of Candida albicans from human immunodeficiency virus-positive individuals prior to first thrush episode. J Clin Microbiol 38:3595-607.

Velraeds MM, Van De Belt-Gritter B, Van Der Mei HC, et al. (1998). Interference in initial adhesion of uropathogenic bacteria and yeasts to silicone rubber by a Lactobacillus acidophilus biosurfactant. J Med Microbiol 47:1081-5.

Verstrepen KJ, Klis FM. (2006). Flocculation, adhesion and biofilm formation in yeasts. Mol Microbiol 60:5-15.

Vidotto V, Mantoan B, Pugliese A, et al. (2003). Adherence of Candida albicans and Candida dubliniensis to buccal and vaginal cells. Rev Iberoam Micol 20:52-4.

Vijaya D, Dhanalakshmi TA, Kulkarni S. (2014). Changing trends of vulvovaginal candidiasis. J Lab Physicians 6:28-30.

Wagner RD, Johnson SJ. (2012). Probiotic Lactobacillus and estrogen effects on vaginal epithelial gene expression responses to Candida albicans. J Biomed Sci 19:58. doi: 10.1186/1423-0127-1958.

Watson C, Calabretto H. (2007). Comprehensive review of conventional and non-conventional methods of management of recurrent vulvovaginal candidiasis. Aust New Zeal J Obstet Gynaecol 47:262-72.

Watson MC, Grimshaw JM, Bond CM, et al. (2002). Oral versus intravaginal imidazole and triazole anti-fungal agents for the treatment of uncomplicated vulvovaginal candidiasis (thrush): a systematic review. BJOG 109:85-95.

Watts DH, Rabe L, Krohn MA, et al. (1999). The effects of three nonoxynol-9 preparations on vaginal flora and epithelium. J Infect Dis 180:426-37.
Weissenbacher TM, Witkin SS, Gingelmaier A, et al. (2009). Relationship between recurrent vulvovaginal candidosis and immune mediators in vaginal fluid. Eur J Obstet Gynecol Reprod Biol 144: 59-63.

White S, Larsen B. (1997). Candida albicans morphogenesis is influenced by estrogen. Cell Mol Life Sci 53:744-9.

Williams DW, Kuriyama T, Silva S, et al. (2011). Candida biofilms and oral candidosis: treatment and prevention. Periodontology 200055 : 250-65.

Wilson RM, Reeves WG. (1986). Neutrophil phagocytosis and killing in insulin-dependent diabetes. Clin Exp Immunol 63:478-84.

Wilson RM, Tomlinson DR, Reeves WG. (1987). Neutrophil sorbitol production impairs oxidative killing in diabetes. Diabet Med 4:37-40.

Wira CR, Fahey JV. (2008). A new strategy to understand how HIV infects women: identification of a window of vulnerability during the menstrual cycle. AIDS 22:1909-17.

Wira CR, Fahey JV, Ghosh M, et al. (2010). Sex hormone regulation of innate immunity in the female reproductive tract: the role of epithelial cells in balancing reproductive potential with protection against sexually transmitted pathogens. Am J Reprod Immunol 63:544-65.

Wira CR, Fahey JV, Sentman CL, et al. (2005a). Innate and adaptive immunity in female genital tract: cellular responses and interactions. Immunol Rev 206:306-35.

Wira CR, Grant-Tschudy KS, Crane-Godreau MA. (2005b). Epithelial cells in the female reproductive tract: a central role as sentinels of immune protection. Am J Reprod Immunol 53:65-76.

Witkin SS. (1991). Immunologic factors influencing susceptibility to recurrent candidal vaginitis. Clin Obstet Gynecol 34:662-8.

Witkin SS, Jeremias J, Ledger WJ. (1989). Vaginal eosinophils and IgE antibodies to Candida albicans in women with recurrent vaginitis. J Med Vet Mycol 27:57-8.

Xu J, Schwartz K, Bartoces M, et al. (2008). Effect of antibiotics on vulvovaginal candidiasis: a MetroNet study. J Am Board Fam Med 21: 261-8.

Xu J, Sobel JD. (2003). Antibiotic-associated vulvovaginal candidiasis. Curr Infect Dis Rep 5:481-7.

Zaugg C, Zepelin MB, Reichard U, et al. (2001). Secreted aspartic proteinase family of Candida tropicalis. Infect Immun 69:405-12.

Zhang X, Essmann M, Burt ET, Larsen B. (2000). Estrogen effects on Candida albicans: a potential virulence-regulating mechanism. J Infect Dis 181:1441-6.

Zitvogel L, Apetoh L, Ghiringhelli F, Kroemer G. (2008). Immunological aspects of cancer chemotherapy. Nat Rev Immunol 8:59-73.

Zordan RE, Galgoczy DJ, Johnson AD. (2006). Epigenetic properties of white-opaque switching in Candida albicans are based on a self-sustaining transcriptional feedback loop. Proc Natl Acad Sci 103:12807-12.

Zordan RE, Miller MG, Galgoczy DJ, et al. (2007). Interlocking transcriptional feedback loops control white-opaque switching in Candida albicans. PLoS Bio 5:256. 